\title{
Worry About Daily Financial Needs and Food Insecurity Among Cancer Survivors in the United States
}

Zhiyuan Zheng, $\mathrm{PhD}^{\text {; }}$; Ahmedin Jemal, DVM, PhDa; Reginald Tucker-Seeley, MA, ScM, ScD; ; Matthew P. Banegas, $\mathrm{PhD}^{\text {; }}$; Xuesong Han, PhDa; Ashish Rai, PhDa; Jingxuan Zhao, MPHa; and K. Robin Yabroff, PhD, MBA ${ }^{a}$

\begin{abstract}
Background: A cancer diagnosis can impose substantial medical financial burden on individuals and may limit their ability to work. However, less is known about worry for nonmedical financial needs and food insecurity among cancer survivors. Methods: The National Health Interview Survey (2013-2017) was used to identify cancer survivors (age 18-39 years, $n=771$; age 40-64 years, $n=4,269$; age $\geq 65$ years, $n=7,101)$ and individuals without a cancer history (age 18-39 years, $n=53,262$; age $40-64$ years, $n=60,141$; age $\geq 65$ years, $n=30,261$ ). For both cancer survivors and the noncancer group, adjusted proportions were generated for (1) financial worry ("very/moderately/not worried") about retirement, standard of living, monthly bills, and housing costs; and (2) food insecurity ("often/sometimes/not true") regarding whether food would run out, the fact that food bought did not last, and the inability to afford balanced meals. Further adjusted analyses examined intensity measures ("severe/moderate/minor or none") of financial worry and food insecurity among cancer survivors only. Results: Compared with individuals without a cancer history, cancer survivors aged 18 to 39 years reported consistently higher "very worried" levels regarding retirement $(25.5 \%$ vs $16.9 \% ; P<.001)$, standard of living (20.4\% vs $12.9 \%$; $P<.001)$, monthly bills $(14.9 \%$ vs $10.3 \% ; P=.002)$, and housing costs $(13.6 \%$ vs $8.9 \%$; $P=.001)$; and higher "often true" levels regarding worry about food running out $(7.9 \%$ vs $4.6 \% ; P=.004)$, food not lasting $(7.6 \%$ vs $3.3 \%$; $P=.003)$, and being unable to afford balanced meals (6.3\% vs $3.4 \%$; $P=.007)$. Findings were not as consistent for cancer survivors aged 40 to 64 years. In contrast, results were generally similar for adults aged $\geq 65$ years with/without a cancer history. Among cancer survivors, $57.6 \%$ (age 18-39 years; $P<.001$ ), 51.9\% (age $40-64$ years; $P<.001$ ), and $23.8 \%$ (age $\geq 65$ years; referent) reported severe/moderate financial worry intensity, and $27.0 \%$ (age 18-39 years; $P<.001$ ), 14.8\% (age 40-64 years; $P<.001$ ), and $6.3 \%$ (age $\geq 65$ years; referent) experienced severe/moderate food insecurity intensity. Lower income and higher comorbidities were generally associated with greater intensities of financial worry and food insecurity in all 3 age groups. Conclusions: Younger cancer survivors experience greater financial worry and food insecurity. In addition to coping with medical costs, cancer survivors with low income and multiple comorbidities struggle to pay for daily living needs, such as food, housing, and monthly bills.
\end{abstract}

J Natl Compr Canc Netw 2020;18(3):315-327 doi: 10.6004/jnccn.2019.7359

a Surveillance and Health Services Research Program, American Cancer Society, Atlanta, Georgia; ' University of Southern California, Los Angeles, California; and ${ }^{\mathrm{C}}$ The Center for Health Research, Kaiser Permanente, Portland, Oregon.

\section{Background}

The costs of medical care after a cancer diagnosis impose substantial financial hardship on cancer survivors and their families in the United States. ${ }^{1,2}$ Studies have shown that cancer survivors have higher medical expenses, ${ }^{3,4}$ incur greater out-of-pocket (OOP) costs for medical bills, ${ }^{5,6}$ and are more likely to forgo/delay prescription medications because of cost compared with individuals without a cancer history. ${ }^{7,8}$ Moreover, cancer survivors are subject to limitations in ability to work ${ }^{9}$ and may leave the labor force because of health problems. ${ }^{10}$ Health-related unemployment may disrupt employerbased health insurance coverage and adversely affect financial well-being due to lost earnings. ${ }^{10-12}$ Rationing limited finances between medical needs and daily living needs, cancer survivors may struggle to pay for food and housing, withdraw from savings set aside for education or retirement, or fall behind on their monthly bills to cope with OOP medical costs. ${ }^{13}$ Moreover, cancer survivors may undergo considerable psychological distress due to depleted financial resources..$^{14,15}$ However, less is known about the extent to which financial worry and food insecurity are associated with cancer survivorship in the United States.

There is increasing awareness about the importance of addressing social determinants of health (SDH) to reduce health disparities, ${ }^{3}$ emphasizing the roles of social, economic, and environmental factors in improving health outcomes. ${ }^{16}$ Healthy People 2020 identifies key areas of SDH embedded in homes, schools, workplaces, neighborhoods, and communities, ${ }^{17}$ including safe housing, access to education, public safety, local markets with affordable and healthy foods, and environments free of life-threatening toxins. However, most existing studies have focused on medical financial hardships, such as OOP expenses, healthcare utilization, or delaying medical care because of cost, ${ }^{18-24}$ whereas 
key aspects of SDH, such as food insecurity and worry about having sufficient resources for nonmedical financial needs during survivorship (eg, monthly bills and housing expenses), are largely uncharted areas of research. Moreover, existing studies have been limited to small sample sizes, select cancer sites, specific geographic regions, or certain medical centers. ${ }^{25-28}$

Our study built on previous findings about medical financial hardship among cancer survivors ${ }^{14,15,29}$ and examined multiple measures of financial worry regarding nonmedical needs and food insecurity using nationally representative data. We hypothesized that cancer survivors experience financial worry and food insecurity at higher levels than individuals without a cancer history. Moreover, because younger age, lower family income, and higher comorbid conditions have all been associated with greater health disparities among cancer survivors, ${ }^{15,30,31}$ we also hypothesized that the patterns of financial worry and food insecurity vary by age, family income, number of comorbidities, and additional variables of interest, such as race/ethnicity, time since diagnosis, and major cancer site.

\section{Methods}

\section{Data Sources}

We used the 2013-2017 National Health Interview Survey (NHIS) to identify adult cancer survivors and those without a cancer history (age $\geq 18$ years). The NHIS is a cross-sectional household survey conducted annually by the National Center for Health Statistics within the Centers for Disease Control and Prevention. ${ }^{32}$ It is a nationally representative sample of the civilian noninstitutionalized US population. Because deidentified NHIS data are publicly available, this study was exempt from Institutional Review Board review. The survey collects information on demographic characteristics, access to and use of healthcare services, and health conditions. The annual household response rate to the NHIS ranged from $66.5 \%$ to $75.7 \%$ during our study period. $^{33,34}$

\section{Analytical Sample and Individual-Level \\ Characteristics}

In the NHIS, cancer history is self-reported at the time of the survey. We defined cancer survivors as those who reported ever being diagnosed with cancer or any malignancy by a doctor or other health professional. Individuals with nonmelanoma skin cancer only or skin cancer of unknown type were excluded. Because $>90 \%$ of Americans aged $\geq 65$ years are covered by the Medicare program, ${ }^{35}$ and younger age has been associated with greater medical financial hardship, ${ }^{15}$ we stratified the sample into 3 age groups: 18 to 39 years, 40 to 64 years, and $\geq 65$ years.
Individual-level demographic and clinical variables included age at the time of the survey, sex, race/ethnicity, educational attainment, marital status, family income level as a percentage of the federal poverty level (FPL; calculation was based on the US Census Bureau federal poverty thresholds given the family's size and number of children $^{34}$ ), geographic region, health insurance coverage, number of comorbid conditions, NHIS survey year, and US geographic region. Comorbid conditions included arthritis, asthma, diabetes, emphysema, coronary heart disease, hypertension, stroke, angina pectoris, and heart attack. For cancer survivors, time since diagnosis was calculated using age at most recent diagnosis and age at the time of the survey. ${ }^{36}$ We defined recently diagnosed $(<2$ years since diagnosis) and previously diagnosed ( $\geq 2$ years since diagnosis) cancer survivors. ${ }^{15,36}$ A binary variable was also created for those with multiple cancers (2-3 cancers vs 1 cancer only).

\section{Financial Worry and Food Insecurity}

We operationalized worry about having sufficient financial resources using 4 individual-level measures that assessed worry about money related to (1) retirement, (2) standard of living, (3) monthly bills, and (4) rent, mortgage, or other housing costs. All 4 financial worry measures were administered to all adults aged $\geq 18$ years during each survey year and referred to "current status" at the time of the survey (supplemental eTable 1, available with this article at JNCCN.org). Response categories to these measures were "very worried," "moderately worried," "not too worried," and "not worried at all." A summary score for financial worry was created by assigning a score to each individual measure ("very worried" $=2$; "moderately worried" $=1$; "not too worried/not worried at all" $=0$ ) and summing the scores for the 4 measures (range, 0-8). We then categorized overall financial worry into 3 intensity levels: minor/none (scores of $0-1$ ), moderate (scores of 2-4), and severe (scores of 5-8).

Similarly, we operationalized food insecurity using 3 family-level measures: (1) "worry about food running out," (2) "food not lasting," and (3) "unable to afford balanced meals." All 3 food insecurity measures were surveyed at the family level for all respondents during each survey year and referred to the status during the past 30 days at the time of the survey (supplemental eTable 1). Responses to these measures were "often true," "sometimes true," and "never true." A summary score for food insecurity was created by assigning individual scores to each response category for all 3 measures ("often true" $=2$; "sometimes true" $=1$; "never true" $=0$ ) and adding the scores for the 3 measures (range, $0-6$ ). We then categorized overall food insecurity into 3 intensity levels: minor/none (scores of $0-1$ ), moderate (scores of 
2-3), and severe (scores of 4-6). The approach of using summary measures had the benefit of synthesizing information from various measures for financial worry and food insecurity experiences into a single score. . $^{74,37}$

Due to the availability of financial worry and food insecurity measures, our study sample was restricted to the years 2013 through 2017, when both financial worry and food insecurity measures were captured consistently. Supplemental eTable 1 shows the exact phrasing of the NHIS questions. Respondents with missing information on either food insecurity measures or financial worry measures were removed from the analyses. The final analytical sample consisted of 12,141 cancer survivors (age 18-39 years: $n=771$; age $40-64$ years: $n=4,269$; age $\geq 65$ years: $n=7,101$ ) and 143,664 individuals without a cancer history (age 18-39 years: $n=53,262$; age $40-64$ years: $n=60,141$; age $\geq 65$ years: $n=30,261$ ).

\section{Statistical Methods}

We compared distributions of individual-level characteristics for cancer survivors and those without a cancer history, stratified by age. Because there is a natural ordering from lower to higher level of financial worry and food insecurity, we used generalized ordinal logistic regression to generate adjusted proportions of individual measures and intensity measures by cancer history, respectively. ${ }^{38}$ We adjusted all multivariable regression models for survey year, age group, sex, race/ethnicity, educational attainment, marital status, number of comorbid conditions, family income level as a percentage of FPL, health insurance coverage, and geographic region. Further analyses focused on cancer survivors only and examined the associations between intensity measures of financial worry and food insecurity by family income, number of comorbidities, race/ethnicity, time since diagnosis, and major cancer site (female breast, colorectal, prostate, and lung), controlling for the same covariates as the main analyses and multiple cancer status ( $\geq 2$ cancers vs 1 cancer only). For direct comparisons between age groups, we conducted additional adjusted analyses using the combined population of cancer survivors from all 3 age groups and generated odds ratios (ORs) of reporting food insecurity and financial worry by age group. We performed the generalized ordinal logistic regressions using STATA, version 14.1 (StataCorp LLP). Statistical comparisons were 2-sided, and significance was defined as $P<.05$.

\section{Results}

Individual-Level Characteristics

Compared with individuals without a cancer history, cancer survivors were more likely to be older and nonHispanic white, have a higher education, and have more comorbid conditions. Moreover, cancer survivors were more likely to be married and aged 18 to 39 years or $\geq 65$ years but less likely to be married and aged 40 to 64 years. Family income and insurance coverage distributions for cancer survivors also varied by age group compared with individuals without a cancer history: for those aged 18 to 39 years, cancer survivors were more likely to have income $<200 \%$ of the FPL and be covered by public insurance only; for those aged 40 to 64 years, cancer survivors had similar income, higher proportions of being covered by public insurance only, and lower proportions of being uninsured; for those aged $\geq 65$ years, cancer survivors were more likely to have an income level $\geq 400 \%$ of the FPL and have Medicare with any private coverage. More than $80 \%$ of cancer survivors were diagnosed $\geq 2$ years before the survey date, and $<9 \%$ had multiple cancer diagnoses (Table 1).

\section{Adjusted Results for Financial Worry and Food Insecurity}

Among individuals aged 18 to 39 years, adjusted analyses showed that compared with individuals without a cancer history, cancer survivors were more likely to report being very worried $(25.5 \%$ vs $16.9 \% ; P<.001)$ about retirement, very worried $(20.4 \%$ vs $12.9 \% ; P<.001)$ or moderately worried (27.6\% vs $23.2 \%$; $P=.036)$ about their standard of living, very worried $(14.9 \%$ vs $10.3 \%$; $P=.002)$ or moderately worried $(25.9 \%$ vs $19.3 \%$; $P=.001)$ about monthly bills, and very worried (13.6\% vs $8.9 \% ; P=.001)$ or moderately worried $(17.3 \%$ vs $14.7 \%$; $P=.013$ ) about housing costs (Table 2). Similarly, cancer survivors were more likely to report "often true" $(7.9 \%$ vs $4.6 \%$; $P=.004$ ) about food running out, "often true" (7.6\% vs $3.3 \% ; P=.003)$ or "sometimes true" $(14.2 \%$ vs $10.5 \% ; P=.010)$ about food not lasting, and "often true" (6.3\% vs $3.4 \% ; P=.007)$ about inability to afford balanced meals compared with individuals without a cancer history.

Among individuals aged 40 to 64 years, compared with those without a cancer history, cancer survivors were more likely to report being very worried $(20.1 \%$ vs $18.3 \% ; P=.015)$ about standard of living and often true (4.3\% vs $3.6 \%$; $P=.032$ ) about inability to afford balanced meals compared with individuals without a cancer history (Table 2). Other estimates of financial worry and food insecurity were similar for cancer survivors and individuals without a cancer history in this age group.

Among individuals aged $\geq 65$ years, compared with individuals without a cancer history, cancer survivors reported similar patterns of financial worry and food insecurity as individuals without a cancer history (Table 2). eTable 2 shows the unadjusted proportions for 


\section{Table 1. Patient Characteristics}

\begin{tabular}{|c|c|c|c|c|c|c|c|c|c|}
\hline \multirow[b]{2}{*}{ Characteristic } & \multicolumn{3}{|c|}{ Aged 18-39 Years } & \multicolumn{3}{|c|}{ Aged 40-64 Years } & \multicolumn{3}{|c|}{ Aged $\geq 65$ Years } \\
\hline & $\begin{array}{l}\text { Cancer } \\
\text { Survivors } \\
\text { (\%) }\end{array}$ & $\begin{array}{l}\text { No Cancer } \\
\text { History }^{\mathrm{a}} \\
(\%)\end{array}$ & $P$ Value $^{\mathrm{b}}$ & $\begin{array}{l}\text { Cancer } \\
\text { Survivors } \\
\text { (\%) }\end{array}$ & $\begin{array}{l}\text { No Cancer } \\
\text { History } \\
(\%)\end{array}$ & $P$ Value ${ }^{b}$ & $\begin{array}{l}\text { Cancer } \\
\text { Survivors } \\
(\%)\end{array}$ & $\begin{array}{l}\text { No Cancer } \\
\text { History }^{\mathrm{a}} \\
(\%)\end{array}$ & $P$ Value $^{\mathrm{b}}$ \\
\hline Total, n & 771 & 53,262 & & 4,269 & 60,141 & & 7,101 & 30,261 & \\
\hline \multicolumn{10}{|l|}{ Age, y } \\
\hline $18-29$ & 31.5 & 55.7 & \multirow{2}{*}{$<.001$} & & & & & & \\
\hline $30-39$ & 68.4 & 44.3 & & & & & & & \\
\hline $40-49$ & & & & 21.1 & 41.2 & \multirow{2}{*}{$<.001$} & & & \\
\hline $50-64$ & & & & 78.9 & 58.8 & & & & \\
\hline $65-80$ & & & & & & & 74.6 & 80.9 & \multirow{2}{*}{$<.001$} \\
\hline$\geq 81$ & & & & & & & 25.4 & 19.1 & \\
\hline Sex & & & $<.001$ & & & $<.001$ & & & $<.001$ \\
\hline Male & 27.5 & 49.8 & & 35.8 & 49.6 & & 47.5 & 43.1 & \\
\hline Female & 72.5 & 50.2 & & 64.2 & 50.4 & & 52.5 & 56.9 & \\
\hline Race/Ethnicity & & & $<.001$ & & & $<.001$ & & & $<.001$ \\
\hline Non-Hispanic white & 72.0 & 56.5 & & 79.1 & 65.2 & & 83.6 & 74.9 & \\
\hline Non-Hispanic black & 6.2 & 13.1 & & 8.3 & 12.0 & & 7.5 & 9.6 & \\
\hline Hispanic & 16.1 & 21.2 & & 7.9 & 14.8 & & 5.1 & 9.2 & \\
\hline Asian and others & 5.7 & 9.2 & & 4.7 & 8.0 & & 3.8 & 6.3 & \\
\hline Educational attainment & & & .178 & & & $<.001$ & & & $<.001$ \\
\hline Less than high school or missing & 12.8 & 11.9 & & 10.1 & 12.5 & & 14.9 & 18.5 & \\
\hline High school graduate & 20.2 & 23.9 & & 25.6 & 24.55 & & 28.9 & 29.3 & \\
\hline Some college or greater & 67.0 & 64.3 & & 64.3 & 63.0 & & 56.2 & 52.2 & \\
\hline Marital status & & & $<.001$ & & & .017 & & & .005 \\
\hline Married & 45.7 & 38.1 & & 62.5 & 64.8 & & 57.6 & 55.4 & \\
\hline Not married or missing & 54.3 & 61.9 & & 37.5 & 35.2 & & 42.4 & 44.6 & \\
\hline Number of comorbid conditions ${ }^{c}$ & & & $<.001$ & & & $<.001$ & & & $<.001$ \\
\hline 0 & 48.9 & 73.4 & & 30.0 & 44.9 & & 12.4 & 18.2 & \\
\hline 1 & 29.1 & 21.7 & & 30.4 & 30.4 & & 26.6 & 29.2 & \\
\hline 2 & 14.6 & 4.0 & & 20.7 & 15.2 & & 29.6 & 26.7 & \\
\hline$\geq 3$ & 7.5 & 0.9 & & 18.9 & 9.6 & & 31.4 & 25.9 & \\
\hline \multicolumn{10}{|l|}{ Time since diagnosis } \\
\hline Recently diagnosed $(<2$ y) & 18.6 & \multirow{2}{*}{ NA } & & 16.3 & & & 2.7 & \multirow{2}{*}{ NA } & \\
\hline Previously diagnosed ( $\geq 2 \mathrm{y}$ ) & 81.4 & & & 83.7 & & & 97.3 & & \\
\hline \multicolumn{10}{|l|}{ Number of cancer diagnoses } \\
\hline 1 & 92.5 & \multirow{2}{*}{ NA } & & 91.0 & & & 97.5 & \multirow{2}{*}{ NA } & \\
\hline $2-3$ & 7.5 & & & 9.0 & & & 2.5 & & \\
\hline \multicolumn{10}{|l|}{ Cancer site ${ }^{d}$} \\
\hline Female breast & 4.9 & \multirow{5}{*}{ NA } & & 21.9 & & & 23.2 & \multirow{5}{*}{ NA } & \\
\hline Colorectal & 3.8 & & & 6.4 & & & 8.1 & & \\
\hline Prostate & 0.3 & & & 8.1 & NA & & 22.2 & & \\
\hline Lung & 1.3 & & & 2.6 & & & 4.5 & & \\
\hline All others & 89.7 & & & 61.0 & & & 41.0 & & \\
\hline
\end{tabular}


Table 1. Patient Characteristics (cont.)

\begin{tabular}{|c|c|c|c|c|c|c|c|c|c|}
\hline Characteristic & \multicolumn{3}{|c|}{ Aged 18-39 Years } & \multicolumn{3}{|c|}{ Aged 40-64 Years } & \multicolumn{3}{|c|}{ Aged $\geq 65$ Years } \\
\hline Family income level as $\%$ of FPLe & & & .009 & & & .239 & & & $<.001$ \\
\hline$<200 \%$ or missing & 42.5 & 35.4 & & 23.6 & 24.2 & & 23.0 & 28.3 & \\
\hline $200 \%-399 \%$ & 22.8 & 28.2 & & 25.1 & 24.5 & & 31.1 & 28.2 & \\
\hline Missing & 4.1 & 5.7 & & 6.3 & 7.3 & & 11.0 & 11.9 & \\
\hline \multicolumn{10}{|c|}{ Health insurance coverage by age group, $\mathrm{y}^{\mathrm{f}}$} \\
\hline $18-64$, any private & 53.3 & 64.0 & \multirow{3}{*}{$<.001$} & 69.3 & 71.1 & \multirow{3}{*}{$<.001$} & & & \\
\hline 18-64, public only & 29.2 & 17.3 & & 23.4 & 16.3 & & & & \\
\hline 18-64, uninsured or missing & 17.5 & 18.7 & & 7.3 & 12.6 & & & & \\
\hline$\geq 65$, other, uninsured, or missing & & & & & & & 3.7 & 6.3 & $<.001$ \\
\hline NHIS year & & & .880 & & & .052 & & & .186 \\
\hline 2013 & 20.2 & 19.7 & & 19.3 & 20.0 & & 18.5 & 18.9 & \\
\hline 2014 & 21.1 & 19.8 & & 19.0 & 20.1 & & 18.3 & 19.8 & \\
\hline 2015 & 18.4 & 19.9 & & 18.7 & 20.1 & & 20.2 & 19.8 & \\
\hline 2016 & 19.4 & 20.2 & & 21.8 & 20.0 & & 21.4 & 20.5 & \\
\hline 2017 & 20.8 & 20.5 & & 21.3 & 19.8 & & 21.6 & 21.0 & \\
\hline US geographic region & & & .006 & & & .067 & & & .252 \\
\hline Northeast & 12.7 & 16.2 & & 17.6 & 18.6 & & 19.0 & 19.5 & \\
\hline
\end{tabular}

A total of 385 cancer survivors and 4,446 individuals without a cancer history who had missing information on either food insecurity measures or financial worry measures were excluded from the sample.

Abbreviations: FPL, federal poverty level; NA, not applicable; NHIS, National Health Interview Survey.

aeference group.

${ }^{\text {b} A l l ~ s t a t i s t i c a l ~ t e s t s ~ w e r e ~} 2$-sided, and all $P$ values were calculated using the Wald chi-square test, accounting for the complex survey design (weights and variance estimation).

'The number of comorbid conditions was defined as the sum of the following conditions that respondents were ever diagnosed with by a doctor or other health professional: arthritis, asthma, diabetes, emphysema, coronary heart disease, hypertension, stroke, angina pectoris, and heart attack. High cholesterol was not included because it was inconsistently measured across years.

'Sample sizes for female breast, colorectal, prostate, and lung cancers were $<50$ among cancer survivors aged 18-39 years.

eFamily income as a percentage of FPL was calculated based on the US Census Bureau federal poverty thresholds given the family's size and number of children (https://www.census.gov/data/tables/time-series/demo/income-poverty/historical-poverty-thresholds.html).

${ }^{\mathrm{f}}$ Medicaid was included in public insurance for all 3 age groups.

responses to individual measures of financial worry and food insecurity among cancer survivors and individuals without a cancer history, stratified by age group. Supplemental eFigures 1 through 4 graphically present the results from Table 2 and eTable 2.

\section{Adjusted Results for Intensities of Financial Worry} and Food Insecurity Among Cancer Survivors

In adjusted analyses among cancer survivors aged 18 to 39 years, $26.4 \%$ and $31.2 \%$ reported severe and moderate intensities of financial worry, respectively, and $12.6 \%$ and
$14.4 \%$ reported severe and moderate intensities of food insecurity, respectively (Figure 1). Among cancer survivors aged 40 to 64 years, $22.2 \%$ and $29.7 \%$ reported severe and moderate intensities of financial worry, respectively, and $6.8 \%$ and $8.0 \%$ reported severe and moderate intensities of food insecurity, respectively (Figure 2 ). Among cancer survivors aged $\geq 65$ years, $6.9 \%$ and $16.9 \%$ reported severe and moderate intensities of financial worry, respectively, and $2.3 \%$ and $3.9 \%$ reported severe and moderate intensities of food insecurity, respectively (Figure 3). Among 
Table 2. Adjusted Results for Financial Worry and Food Insecurity

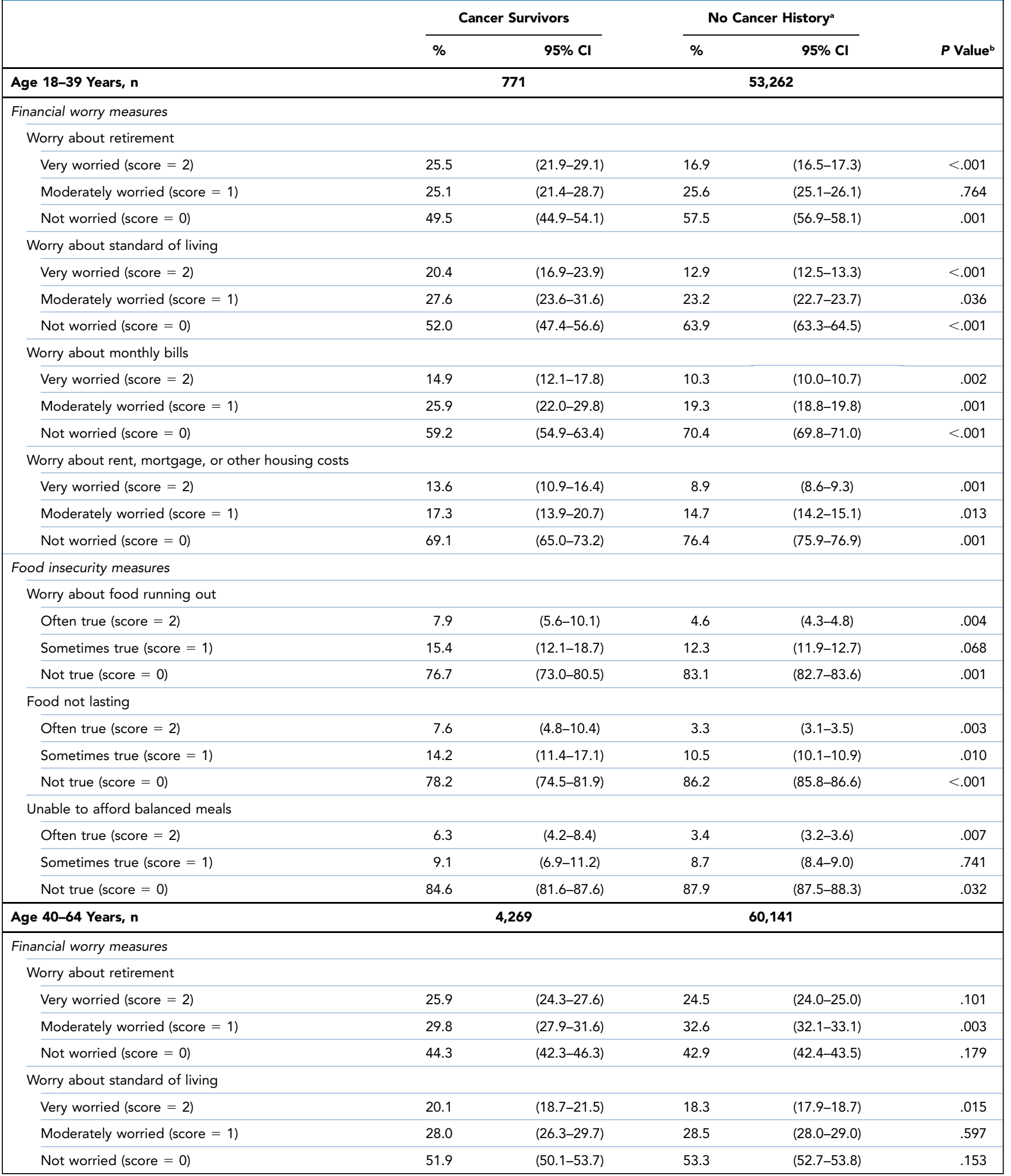




\section{Table 2. Adjusted Results for Financial Worry and Food Insecurity (cont.)}

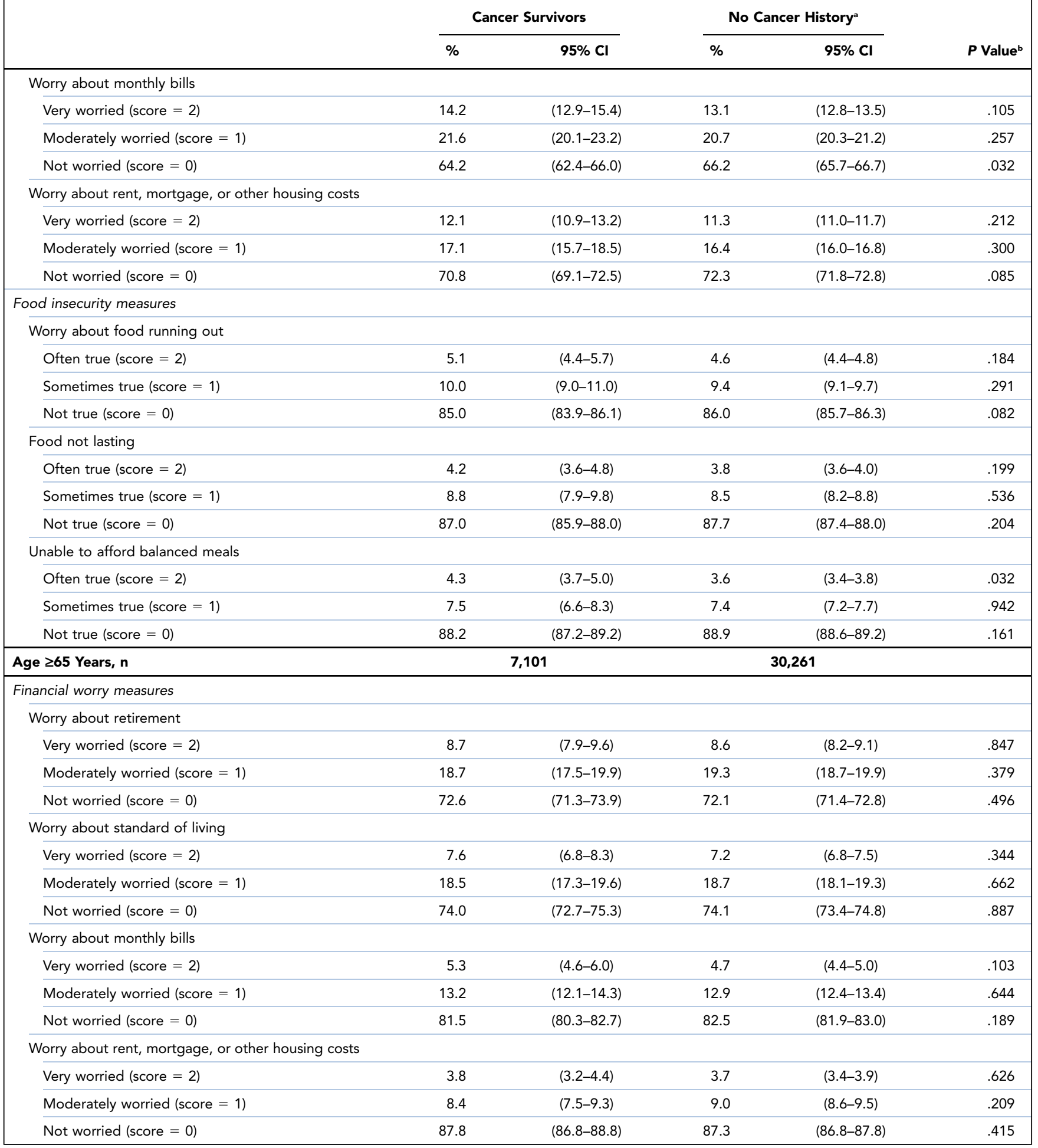


Table 2. Adjusted Results for Financial Worry and Food Insecurity (cont.)

\begin{tabular}{|c|c|c|c|c|c|}
\hline & \multicolumn{2}{|c|}{ Cancer Survivors } & \multicolumn{2}{|c|}{ No Cancer History ${ }^{a}$} & $P$ Value ${ }^{b}$ \\
\hline \multicolumn{6}{|l|}{ Food insecurity measures } \\
\hline \multicolumn{6}{|l|}{ Worry about food running out } \\
\hline Often true $($ score $=2)$ & 2.6 & $(2.1-3.0)$ & 2.2 & $(2.0-2.4)$ & 170 \\
\hline Sometimes true $($ score $=1)$ & 5.5 & $(4.8-6.2)$ & 5.7 & $(5.4-6.0)$ & .595 \\
\hline \multicolumn{6}{|l|}{ Food not lasting } \\
\hline Often true $($ score $=2)$ & 2.0 & $(1.6-2.4)$ & 1.8 & $(1.6-2.0)$ & .467 \\
\hline Sometimes true $($ score $=1)$ & 5.0 & $(4.4-5.6)$ & 5.3 & $(5.0-5.7)$ & .343 \\
\hline Not true $($ score $=0$ ) & 93.0 & (92.3-93.8) & 92.8 & $(92.5-93.2)$ & .708 \\
\hline \multicolumn{6}{|l|}{ Unable to afford balanced meals } \\
\hline
\end{tabular}

Detailed survey questions are shown in supplemental eTable 1, available with this article at JNCCN.org.

Abbreviation: FPL, federal poverty level.

aComparison group.

${ }^{b}$ All statistical tests were 2-sided, and all $P$ values were derived from generalized multivariable ordinal logistic regressions. All regressions controlled for survey year, age group, sex, race/ethnicity, educational attainment, marital status, number of comorbid conditions, family income level as a percentage of FPL, health insurance coverage, and geographic region.

cancer survivors of all 3 age groups, both lower family income and higher number of comorbidities were generally associated with higher intensities of financial worry and food insecurity (see Figures 1-3). However, in all 3 age groups of cancer survivors, we did not find systematic differences in financial worry intensity or food insecurity intensity by race/ethnicity, time since diagnosis, or major cancer site (supplemental eFigures 5-7).

When comparing different age groups among cancer survivors (with those aged $\geq 65$ years as the referent), we found that younger age was associated with a greater likelihood of reporting higher intensities (eg, severe level vs moderate and minor levels) of financial worry (eg, age 18-39 years: OR, 5.28; $P<.001$; age $40-64$ years: OR, $5.01 ; P<.001)$ and food insecurity (eg, age 18-39 years: OR, 6.87; $P<.001$; age 40-64 years: OR, 4.04; $P<.001$; Table 3 ).

\section{Discussion}

In this study, we found that cancer survivors aged 18 to 39 years consistently reported higher financial worry about money for retirement, standard of living, monthly bills, and housing costs than did their counterparts without a cancer history. They also were more likely to experience food insecurity, including worry about food running out, food not lasting, and being unable to afford balanced meals. Findings were not as consistent for cancer survivors aged 40 to 64 years. In contrast, estimates of financial worry and food insecurity among cancer survivors aged $\geq 65$ years were similar to those among individuals without a cancer history. Moreover, younger age, lower family income, and higher number of comorbid conditions were generally associated with increased intensities of financial worry and food insecurity among cancer survivors. Our findings are relevant and timely to policymakers and cancer survivorship programs given the increasing attention to SDH and the emphasis on tackling broad-range social, economic, and behavioral factors to reduce cancerrelated health disparities. ${ }^{17,39,40}$

The findings that cancer survivors aged 18 to 39 years and those aged 40 to 64 years are particularly vulnerable to financial worry and food insecurity compared with cancer survivors aged $\geq 65$ years are consistent with previous research on medical financial hardship during cancer survivorship. ${ }^{7,15,19}$ Like most working-age adults in the United States, cancer survivors aged 18 to 64 years often have employer-based health insurance..$^{35,41} \mathrm{~A}$ cancer diagnosis can increase work limitations and absenteeism because of health reasons, reduce individuals' income, or even cause younger cancer survivors to lose health insurance coverage because they are unable to work. With a cancer diagnosis at an earlier stage of life, younger cancer survivors may have fewer opportunities to accumulate wealth but still need to pay off student 


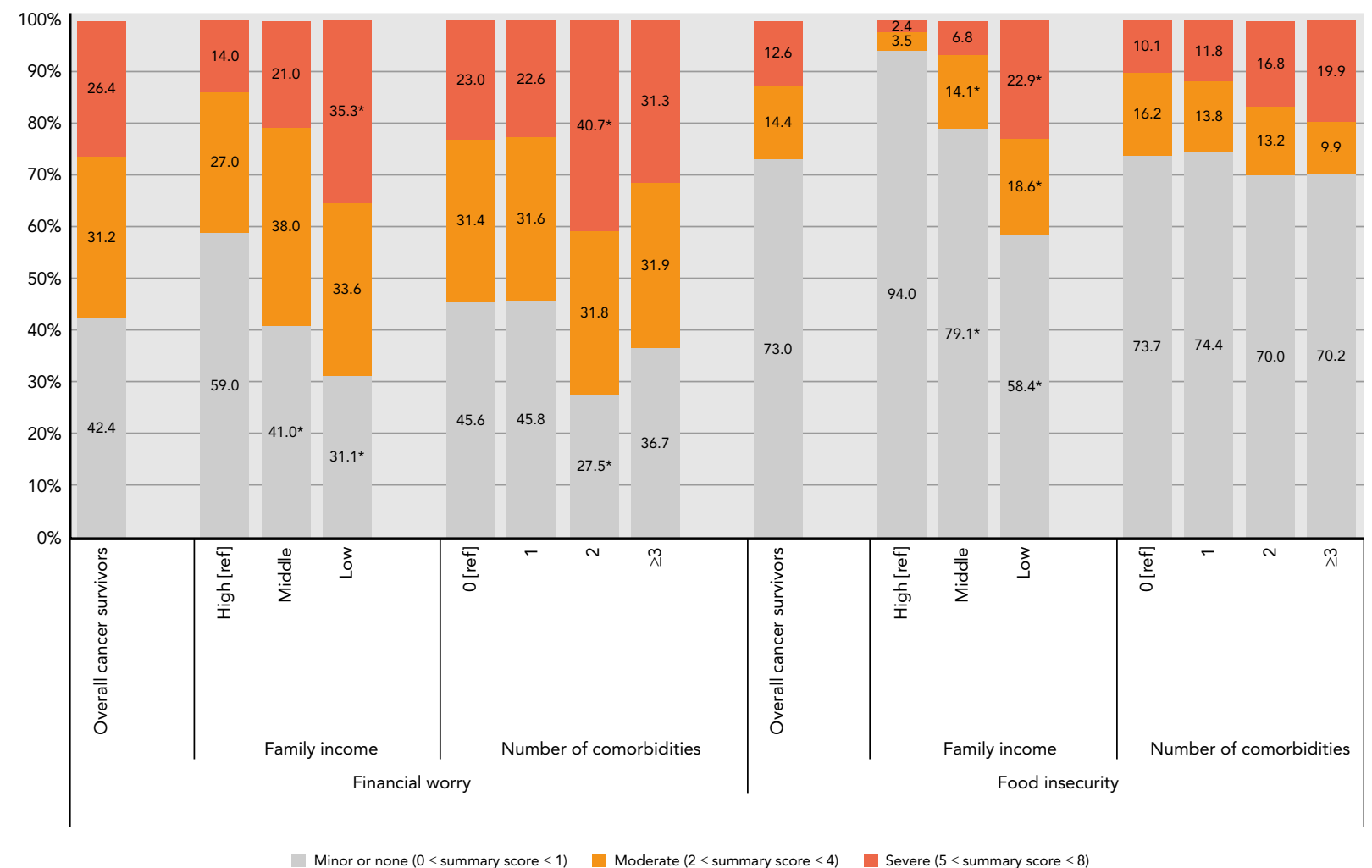

Figure 1. Adjusted intensity of financial worry and food insecurity among cancer survivors aged 18-39 years $(n=771)$, stratified by family income (from high to low income: $n=199, n=185$, and $n=358$, respectively) and number of comorbidities (from 0 to $\geq 3$ comorbidities: $n=379, n=225$, $n=111$, and $n=56$, respectively).

All regressions controlled for survey year, age group, sex, race/ethnicity, educational attainment, marital status, health insurance, and geographic region. The number of comorbid conditions or family income level as a percentage of the federal poverty level was included in the adjusted analyses unless the analyses were stratified by it. ${ }^{*} P<.05$.

loans or fulfill mortgage obligations or have child-rearing responsibilities. ${ }^{31,42}$ In the meantime, a cancer diagnosis and its treatments can increase downstream healthcare needs because of higher risks of secondary cancers, cardiotoxicity, lymphedema, pain and fatigue, cognitive dysfunction, and psychological distress. ${ }^{43}$ It is likely that younger cancer survivors must sacrifice their other economic needs, such as retirement planning and investments in education, and reduce expenses for living necessities, such as food and housing, as a tradeoff for additional medical care. In contrast, $>90 \%$ of the population aged $\geq 65$ years has Medicare ${ }^{35}$ insurance coverage and potentially has accumulated enough financial assets and savings to help pay for OOP medical expenses. Moreover, our results show that compared with those without a cancer history, younger cancer survivors have lower income and are less likely to be insured by private health plans, whereas older cancer survivors have higher income and are more likely to have supplemental private coverage in additional to Medicare. Therefore, targeted interventions for young adult cancer survivors may be necessary, especially those with low family income and multiple comorbidities, to prevent financial worry and food insecurity.

Our study focused on the differences in prevalence of financial worry and food insecurities by cancer history. We did not examine specific health or social policies that could potentially reduce nonmedical financial hardship, but such policies at the federal level may help cancer survivors with financial worry and food insecurity. For example, last year, Congress passed the Deferment for Active Cancer Treatment Act of 2018, which allows patients with cancer to postpone payments on public student loans while they are actively receiving cancer treatment. ${ }^{44}$ In addition, the Centers for Medicare \& Medicaid Services (CMS) has also expanded Medicare Advantage coverage to allow insurers to include healthy groceries, rides to medical appointments, and homedelivered meals in their new benefits. ${ }^{45}$ The Center for Medicare \& Medicaid Innovation at CMS developed a screening tool to detect patients with unmet healthrelated social needs within the Accountable Health Communities (AHC) Model. ${ }^{46}$ This screening tool is designed to identify housing instability, food insecurity, 


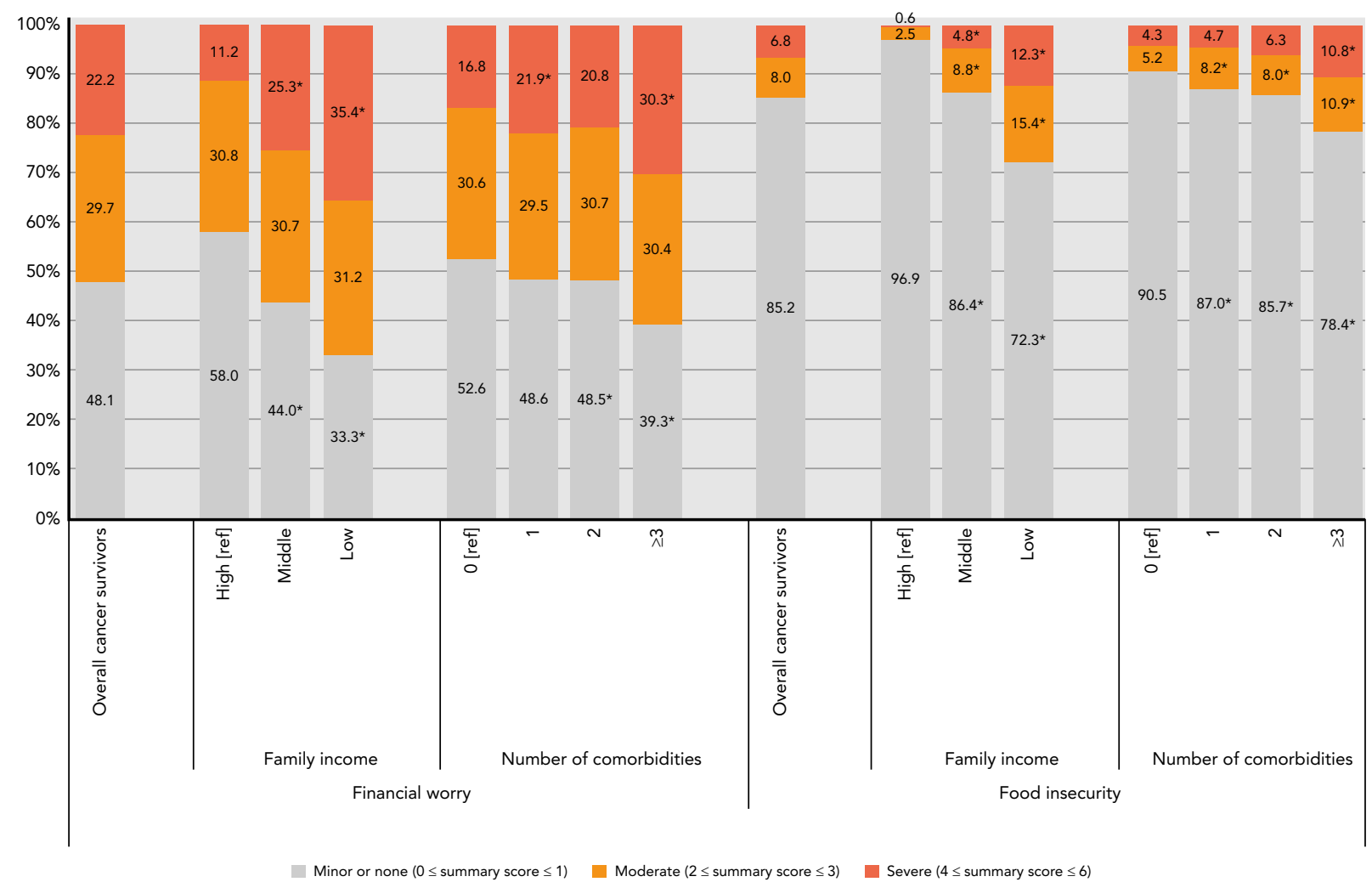

Figure 2. Adjusted intensity of financial worry and food insecurity among cancer survivors aged $40-64$ years ( $n=4,269)$, stratified by family income (from high to low income: $n=1,693, n=1,024$, and $n=1,317$, respectively) and number of comorbidities (from 0 to $\geq 3$ comorbidities: $n=1,203$, $\mathrm{n}=1,312, \mathrm{n}=878$, and $\mathrm{n}=876$, respectively).

All regressions controlled for survey year, age group, sex, race/ethnicity, educational attainment, marital status, health insurance, and geographic region. The number of comorbid conditions or family income level as a percentage of the federal poverty level was included in the adjusted analyses unless the analyses were stratified by it. ${ }^{\star} P<.05$.

transportation problems, utility needs, and interpersonal safety, which can help providers inform patients' treatment plans and make referrals to community services as needed. Innovative financial navigator programs have also shown favorable results in addressing concerns about medical costs among those with nonmedical social needs. ${ }^{47}$ Social Security provides additional income for older cancer survivors and also helps those with certain types of cancer through the Compassionate Allowances program, which provides disability benefits. ${ }^{48}$ Although some of these policies are not cancer-specific, the benefits offered through these programs may provide much-needed help for older cancer survivors with low socioeconomic status.

Some state-level Medicaid policies may also impact the social needs of cancer survivors. ${ }^{49}$ To address $\mathrm{SDH}$, some states have established initiatives to support housing-related activities among Medicaid enrollees, including referral to support services and case management services that retain individuals in stable housing. ${ }^{50}$ In addition, some state Medicaid programs include meal delivery and food assistance as part of posthospitalization discharge care plans. ${ }^{49}$ Employment services to Medicaid enrollees, such as assistance with identifying and obtaining employment, working with employers on job customization, and job coaching and/or consultation with employers, are supported in some states. ${ }^{49}$ However, differences across states regarding these various policies may actually exacerbate regional health disparities for cancer survivors. Additional research evaluating the effects of state-level policies to address social needs during cancer survivorship is warranted.

As shown in this study, among both younger and older cancer survivors, low-income families are particularly vulnerable to financial worry and food insecurity compared with high-income families. Balancing between medical and nonmedical financial needs may create additional psychological distress on top of financial hardship due to medical bills. ${ }^{51-53}$ However, there is a lack of theoretical frameworks incorporating both the medical and nonmedical domains of financial hardship to examine their interrelationships between cancer survivors 


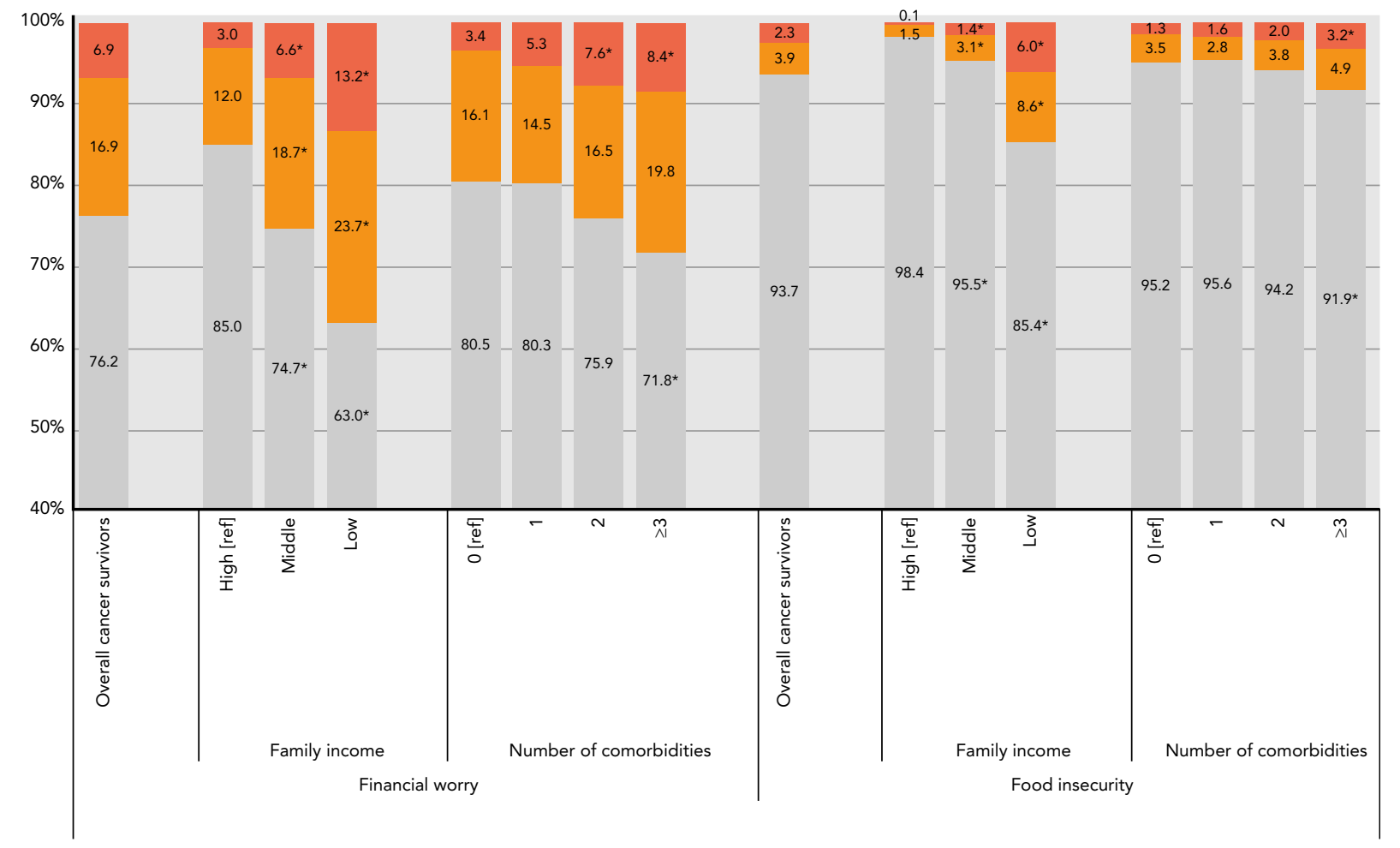

Minor or none $(0 \leq$ summary score $\leq 1) \quad$ Moderate $(2 \leq$ summary score $\leq 3) \quad$ Severe $(4 \leq$ summary score $\leq 6)$

Figure 3. Adjusted intensity of financial worry and food insecurity among cancer survivors aged $\geq 65$ years $(n=7,101)$, stratified by family income (from high to low income: $n=2,107, n=2,207$, and $n=2,032$, respectively) and number of comorbidities (from 0 to $\geq 3$ comorbidities: $n=833$, $\mathrm{n}=1,870, \mathrm{n}=2,114$, and $\mathrm{n}=2,284$, respectively).

All regressions controlled for survey year, age group, sex, race/ethnicity, educational attainment, marital status, health insurance, and geographic region. The number of comorbid conditions or family income level as a percentage of the federal poverty level was included in the adjusted analyses unless the analyses were stratified by it. ${ }^{*} P<.05$.

and individuals without a cancer history. Future studies should also evaluate the relative importance of various domains of financial hardship, including medical and nonmedical, on health outcomes for cancer survivors.
Limitations to our study are worth noting. Measures of food insecurity, financial worry, and cancer history are self-reported and thus subject to recall bias. It would be worthwhile to examine the variations in spending

\section{Table 3. Adjusted Results for Intensities of Financial Worry and Food Insecurity Among Cancer Survivors}

\begin{tabular}{|c|c|c|c|c|c|c|}
\hline \multirow[b]{2}{*}{ Intensity Measure Level } & \multicolumn{3}{|c|}{ Financial Worry } & \multicolumn{3}{|c|}{ Food Insecurity } \\
\hline & OR & $95 \% \mathrm{Cl}$ & $P$ Value ${ }^{a}$ & OR & $95 \% \mathrm{Cl}$ & $P$ Value ${ }^{a}$ \\
\hline \multicolumn{7}{|c|}{ Reporting moderate or severe vs minor/none } \\
\hline Age $\geq 65 y$ & & Ref & & & Ref & \\
\hline Age $40-64$ y & 4.36 & $(3.84-4.95)$ & $<.001$ & 3.75 & $(3.10-4.53)$ & $<.001$ \\
\hline Age $18-39$ y & 4.62 & $(3.68-5.80)$ & $<.001$ & 6.65 & $(4.83-9.14)$ & $<.001$ \\
\hline \multicolumn{7}{|c|}{ Reporting severe vs moderate or minor/none } \\
\hline Age $\geq 65 y$ & & Ref & & & Ref & \\
\hline Age $40-64$ y & 5.01 & $(4.21-5.97)$ & $<.001$ & 4.04 & $(3.12-5.23)$ & $<.001$ \\
\hline Age $18-39$ y & 5.28 & $(4.00-6.97)$ & $<.001$ & 6.87 & $(4.62-10.22)$ & $<.001$ \\
\hline
\end{tabular}

Abbreviations: $F P L$, federal poverty level; OR, odds ratio.

aAll statistical tests were 2-sided, and all $P$ values were derived from generalized multivariable ordinal logistic regressions. All regressions controlled for survey year, age group, sex, race/ethnicity, educational attainment, marital status, number of comorbid conditions, family income level as a percentage of FPL, health insurance coverage, and geographic region. 
on food, housing, and other monthly bills based on cancer history. However, data on exact spending are not collected by the NHIS. Detailed treatment history and clinical information about the cancer diagnosis (eg, stage at diagnosis) were not available either. However, we controlled for the number of comorbid conditions and highlighted that higher comorbidities are associated with greater intensities of financial worry and food insecurity among cancer survivors across age groups. In addition, consistent with other population-based household surveys, $>80 \%$ of cancer survivors in our sample were longer-term survivors with at least 2 years since diagnosis. However, we have compared recently and previously diagnosed cancer survivors and found that they reported similar intensities of financial worry and food insecurities; many of these patients were survivors of breast or prostate cancers, who typically have higher incomes than patients diagnosed with other cancers (eg, lung). ${ }^{6}$ Therefore, our results may not be generalizable to patients with cancers that have short-term survival or those that are more common in populations with lower income, and may understate food insecurity and nonmedical financial hardship for those groups. Nevertheless, our study underscores the long and lasting effects of cancer and its treatments on cancer survivors' social and economic well-being using nationally representative data.

\section{Conclusions}

Younger cancer survivors are managing a higher burden of financial worry and food insecurity compared with individuals without a cancer history, especially those aged 18 to 64 years. Lower socioeconomic status and higher comorbidities are associated with higher intensities of financial worry and food insecurity among cancer survivors. In addition to coping with medical financial hardship, cancer survivors may struggle to pay for daily living needs, such as food, housing, and monthly bills. Given the impact of financial hardship and worry on health, well-being, and healthcare use, interventions and policy efforts should address reducing food insecurity and financial worry among cancer survivors.

Submitted May 1, 2019; accepted for publication September 12, 2019

Author contributions: Study concept and design: All authors. Statistical analysis: Zheng. Manuscript preparation: Zheng. Interpretation of results, manuscript revision, approval of final version: All authors.

Disclosures: Dr. Zheng has disclosed that he has received grant/research support from AstraZeneca, and that he is employed by the American Cancer Society, which receives grants from private and corporate foundations, including foundations associated with companies in the health sector for research. Dr. Banegas has disclosed that has received grant/research support from AstraZeneca. The remaining authors have disclosed that they have not received any financial consideration from any person or organization to support the preparation, analysis, results, or discussion of this article.

Correspondence: Zhiyuan Zheng, PhD, Surveillance and Health Services Research Program, American Cancer Society, 250 Williams Street, Atlanta, GA 30303. Email: jason.zheng@cancer.org

\section{References}

1. Yabroff KR, Lund J, Kepka D, et al. Economic burden of cancer in the United States: estimates, projections, and future research. Cancer Epidemiol Biomarkers Prev 2011;20:2006-2014.

2. Yabroff KR, Lamont EB, Mariotto A, et al. Cost of care for elderly cancer patients in the United States. J Natl Cancer Inst 2008;100:630-641.

3. Mariotto $A B$, Yabroff $K R$, Shao $Y$, et al. Projections of the cost of cancer care in the United States: 2010-2020. J Natl Cancer Inst 2011;103:117-128.

4. Zheng Z, Yabroff KR, Guy GP Jr, et al. Annual medical expenditure and productivity loss among colorectal, female breast, and prostate cancer survivors in the United States. J Natl Cancer Inst 2016:108:djv382.

5. Guy GP Jr, Ekwueme DU, Yabroff KR, et al. Economic burden of cancer survivorship among adults in the United States. J Clin Oncol 2013;31: 3749-3757

6. Guy GP Jr, Yabroff KR, Ekwueme DU, et al. Healthcare expenditure burden among non-elderly cancer survivors, 2008-2012. Am J Prev Med 2015; 49(Suppl 5):S489-497

7. Zheng Z, Han X, Guy GP Jr, et al. Do cancer survivors change their prescription drug use for financial reasons? Findings from a nationally representative sample in the United States. Cancer 2017;123:1453-1463.

8. Zhao J, Zheng Z, Han X, et al. Cancer history, health insurance coverage, and cost-related medication nonadherence and medication cost-coping strategies in the United States. Value Health 2019;22:762-767.

9. Ekwueme DU, Yabroff KR, Guy GP Jr, et al. Medical costs and productivity losses of cancer survivors-United States, 2008-2011. MMWR Morb Mortal Wkly Rep 2014;63:505-510.

10. de Boer AG, Taskila T, Ojajärvi A, et al. Cancer survivors and unemployment: a meta-analysis and meta-regression. JAMA 2009;301:753-762.

11. Whitney RL, Bell JF, Reed SC, et al. Predictors of financial difficulties and work modifications among cancer survivors in the United States. J Cancer Surviv 2016;10:241-250.
12. Sabatino SA, Coates RJ, Uhler RJ, et al. Health insurance coverage and cost barriers to needed medical care among U.S. adult cancer survivors age $<65$ years. Cancer 2006;106:2466-2475

13. Zafar SY, Peppercorn JM, Schrag D, et al. The financial toxicity of cancer treatment: a pilot study assessing out-of-pocket expenses and the insured cancer patient's experience. Oncologist 2013;18:381-390.

14. Yabroff KR, Dowling EC, Guy GP, et al. Financial hardship associated with cancer in the United States: findings from a population-based sample of adult cancer survivors. J Clin Oncol 2016;34:259-267

15. Zheng Z, Jemal A, Han X, et al. Medical financial hardship among cancer survivors in the United States. Cancer 2019;125:1737-1747.

16. World Health Organization, Commission on Social Determinants of Health Closing the Gap in a Generation: Health Equity Through Action on the Social Determinants of Health. Available at: https://www.who.int/social_ determinants/thecommission/finalreport/en/. Accessed September 18, 2019

17. Secretary's Advisory Committee on Health Promotion and Disease Prevention Objectives for 2020. Healthy People 2020: An Opportunity to Address the Societal Determinants of Health in the United States. Available at: http://www.healthypeople.gov/2010/hp2020/advisory/ SocietalDeterminantsHealth.htm. Accessed September 18, 2019.

18. Yabroff K, Short PF, Machlin S, et al. Access to preventive health care for cancer survivors. Am J Prev Med 2013;45:304-312.

19. Weaver KE, Rowland JH, Bellizzi KM, et al. Forgoing medical care because of cost: assessing disparities in healthcare access among cancer survivors living in the United States. Cancer 2010;116:3493-3504.

20. Gonzales F, Zheng Z, Yabroff KR. Trends in financial access to prescription drugs among cancer survivors. J Natl Cancer Inst 2018;110:216-219.

21. Doshi JA, Li P, Huo H, et al. Association of patient out-of-pocket costs with prescription abandonment and delay in fills of novel oral anticancer agents. J Clin Oncol 2018;36:476-482. 
22. Goldman DP, Joyce GF, Zheng Y. Prescription drug cost sharing: associations with medication and medical utilization and spending and health. JAMA 2007;298:61-69.

23. Jones SMW, Walker R, Fujii M, et al. Financial difficulty, worry about affording care, and benefit finding in long-term survivors of cancer. Psychooncology 2018;27:1320-1326.

24. Nathan PC, Henderson TO, Kirchhoff AC, et al. Financial hardship and the economic effect of childhood cancer survivorship. J Clin Oncol 2018;36: 2198-2205.

25. Simmons LA, Modesitt SC, Brody AC, et al. Food insecurity among cancer patients in Kentucky: a pilot study. J Oncol Pract 2006;2:274-279.

26. Gany F, Lee T, Ramirez J, et al. Do our patients have enough to eat? Food insecurity among urban low-income cancer patients. J Health Care Poor Underserved 2014;25:1153-1168.

27. Huntington SF, Weiss BM, Vogl DT, et al. Financial toxicity in insured patients with multiple myeloma: a cross-sectional pilot study. Lancet Haematol 2015;2:e408-416.

28. Regenbogen SE, Veenstra CM, Hawley ST, et al. The personal financial burden of complications after colorectal cancer surgery. Cancer 2014;120: 3074-3081.

29. Yabroff KR, Zhao J, Zheng Z, et al. Medical financial hardship among cancer survivors in the United States: what do we know? What do we need to know? Cancer Epidemiol Biomarkers Prev 2018;27:1389-1397.

30. Taplin SH, Barlow W, Urban N, et al. Stage, age, comorbidity, and direct costs of colon, prostate, and breast cancer care. J Natl Cancer Inst 1995; 87:417-426.

31. Ramsey S, Blough D, Kirchhoff A, et al. Washington State cancer patients found to be at greater risk for bankruptcy than people without a cancer diagnosis. Health Aff (Millwood) 2013;32:1143-1152.

32. National Center for Health Statistics. National Health Interview Survey. Available at: http://www.cdc.gov/nchs/nhis.htm. Accessed March 11, 2019.

33. National Center for Health Statistics. Survey description, National Health Interview Survey, 2013. Hyattsville, MD: Division of Health Interview Statistics, National Center for Health Statistics; 2014.

34. National Center for Health Statistics. Survey description, National Health Interview Survey, 2017. Hyattsville, MD: Division of Health Interview Statistics, National Center for Health Statistics; 2018.

35. Berchick ER, Barnett JC, Upton RD. Health Insurance Coverage in the United States: 2018. Current Population Reports, P60-267(RV). Washington, DC; US Government Printing Office: 2019.

36. Kent EE, Forsythe LP, Yabroff KR, et al. Are survivors who report cancerrelated financial problems more likely to forgo or delay medical care? Cancer 2013;119:3710-3717.

37. Altice CK, Banegas MP, Tucker-Seeley RD, et al. Financial hardships experienced by cancer survivors: a systematic review. J Natl Cancer Inst 2017:109:djw205

38. Williams R. Gologit2 documentation. Available at: https://www3.nd.edu/ $\sim$ rwilliam/stata/gologit2.pdf. Accessed September 18, 2019.
39. Adler NE, Cutler DM, Fielding JE, et al. Addressing social determinants of health and health disparities: a vital direction for health and health care. Available at: https://doi.org/10.31478/201609t. Accessed September 18, 2019.

40. Chisolm DJ, Brook DL, Applegate MS, et al. Social determinants of health priorities of state Medicaid programs. BMC Health Serv Res 2019;19:167.

41. Kaiser Family Foundation. 2018 Employer Health Benefits Survey. Available at: https://www.kff.org/health-costs/report/2018-employerhealth-benefits-survey/. Accessed September 19, 2019

42. Weaver KE, Rowland JH, Alfano CM, et al. Parental cancer and the family: a population-based estimate of the number of US cancer survivors residing with their minor children. Cancer 2010;116: 4395-4401.

43. Institute of Medicine and National Research Council. From Cancer Patient to Cancer Survivor: Lost in Transition. Washington, DC: The National Academies Press; 2006.

44. Deferment for Active Cancer Treatment Act of 2018. S 3207, 115th Cong (2017-2018)

45. Jaffe S. Medicare advantage plans cleared to go beyond medical coverage—even groceries. Available at: https://khn.org/news/medicareadvantage-plans-cleared-to-go-beyond-medical-coverage-evengroceries/. Published April 3, 2018. Accessed January 4, 2020

46. Centers for Medicare \& Medicaid Services. The accountable health communities health-related social needs screening tool. Available at: https://innovation.cms.gov/Files/worksheets/ahcm-screeningtool.pdf. Accessed December 20, 2019.

47. Banegas MP, Dickerson JF, Friedman NL, et al. Evaluation of a novel financial navigator pilot to address patient concerns about medical care costs. Perm J 2019;23:18-084.

48. Social Security Administration. Compassionate Allowances. Available at: https://www.ssa.gov/compassionateallowances/. Accessed June 18, 2019.

49. Artiga S, Hinton E. Beyond Health Care: The Role of Social Determinants in Promoting Health and Health Equity. Kaiser Family Foundation website. Available at: https://www.kff.org/disparities-policy/issue-brief/beyondhealth-care-the-role-of-social-determinants-in-promoting-health-andhealth-equity/. Accessed September 19, 2019.

50. Wachino V. Coverage of Housing-Related Activities and Services for Individuals with Disabilities. Baltimore, MD: Center for Medicaid \& CHIP Servcies; June 26, 2015. Available at: https://www.medicaid.gov/sites/ default/files/federal-policy-guidance/downloads/CIB-06-26-2015.pdf. Accessed February 25, 2020.

51. Fenn KM, Evans SB, McCorkle R, et al. Impact of financial burden of cancer on survivors' quality of life. J Oncol Pract 2014;10:332-338.

52. Lathan CS, Cronin A, Tucker-Seeley R, et al. Association of financial strain with symptom burden and quality of life for patients with lung or colorecta cancer. J Clin Oncl 2016;34:1732-1740.

53. Tucker-Seeley RD, Abel GA, Uno H, et al. Financial hardship and the intensity of medical care received near death. Psychooncology 2015;24:572-578. 
Supplemental online content for:

\section{Worry About Daily Financial Needs and Food Insecurity Among Cancer Survivors in the United States}

Zhiyuan Zheng, PhD; Ahmedin Jemal, DVM, PhD; Reginald Tucker-Seeley, MA, ScM, ScD; Matthew P. Banegas, PhD; Xuesong Han, PhD; Ashish Rai, PhD; Jingxuan Zhao, MPH; and K. Robin Yabroff, PhD, MBA

J Natl Compr Canc Netw 2020;18(3):315-327

eFigure 1: Adjusted Results of Study Population Reporting Individual Financial Worry Measures eFigure 2: Adjusted Results of Study Population Reporting Individual Food Insecurity Measures eFigure 3: Unadjusted Results of Study Population Reporting Individual Financial Worry Measures eFigure 4: Unadjusted Results of Study Population Reporting Individual Food Insecurity Measures eFigure 5: Adjusted Results of Financial Worry Intensity and Food Insecurity Intensity Among Cancer Survivors Aged 18-39 Years

eFigure 6: Adjusted Results of Financial Worry Intensity and Food Insecurity Intensity Among Cancer Survivors Aged 40-64 Years

eFigure 7: Adjusted Results of Financial Worry Intensity and Food Insecurity Intensity Among Cancer Survivors Aged $\geq 65$ Years

eTable 1: NHIS Measures of Food Insecurity and Financial Worry

eTable 2: Unadjusted Results for Financial Worry and Food Insecurity 


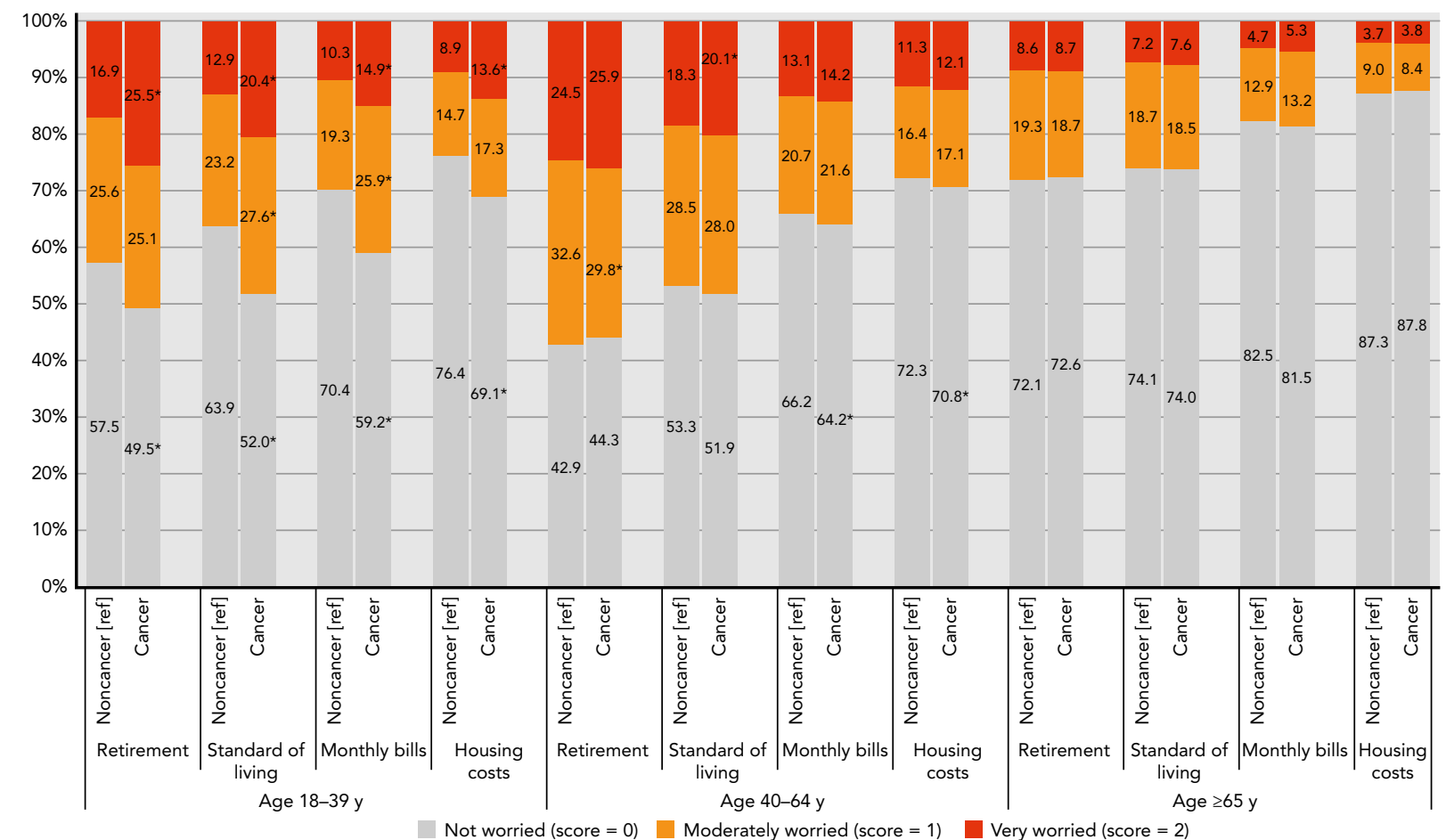

eFigure 1. Adjusted results of study population reporting individual financial worry measures.

${ }^{*} P<.05$.

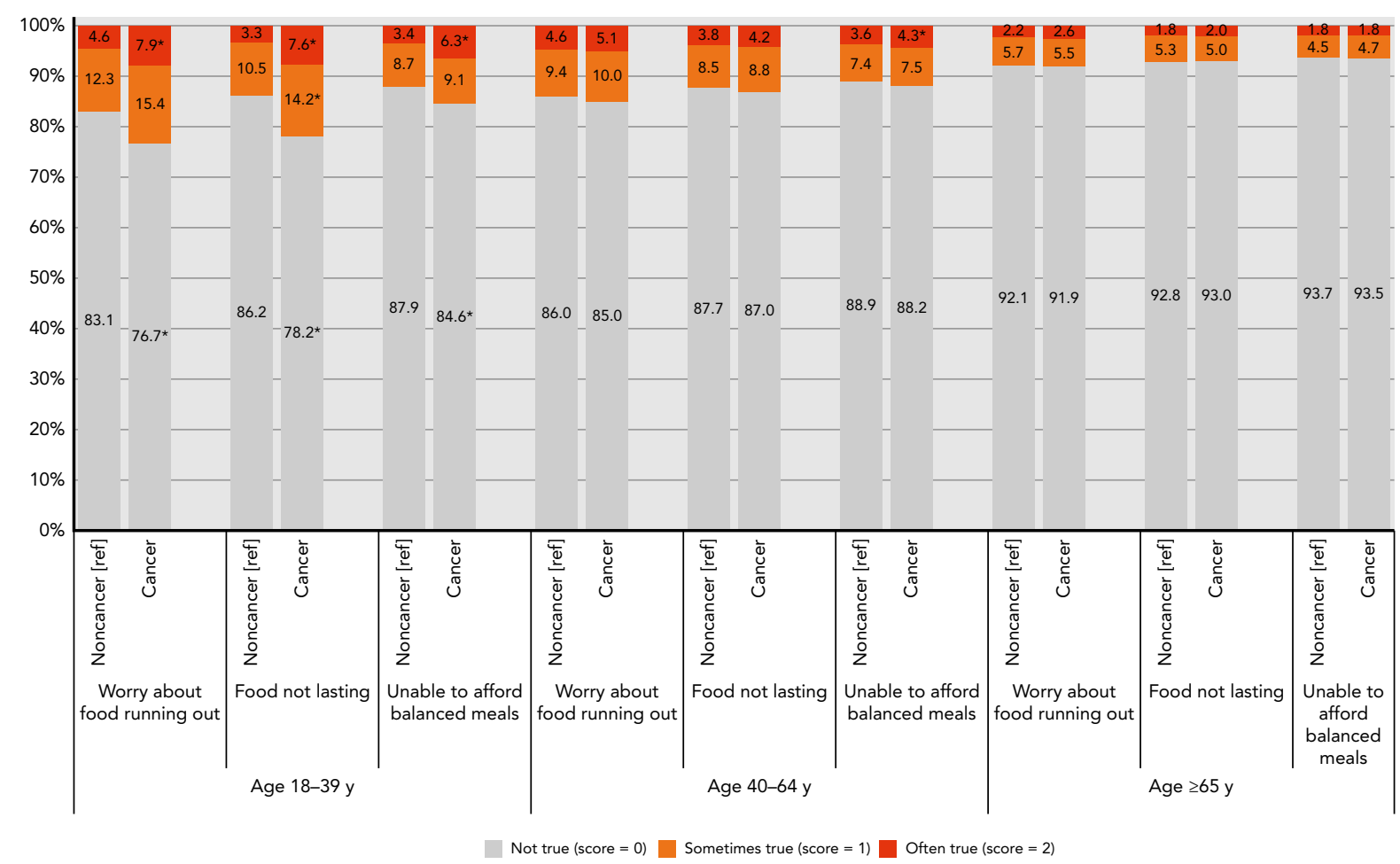

eFigure 2. Adjusted results of study population reporting individual food insecurity measures.

${ }^{\star} P<.05$. 


\section{2 - Zheng et al}

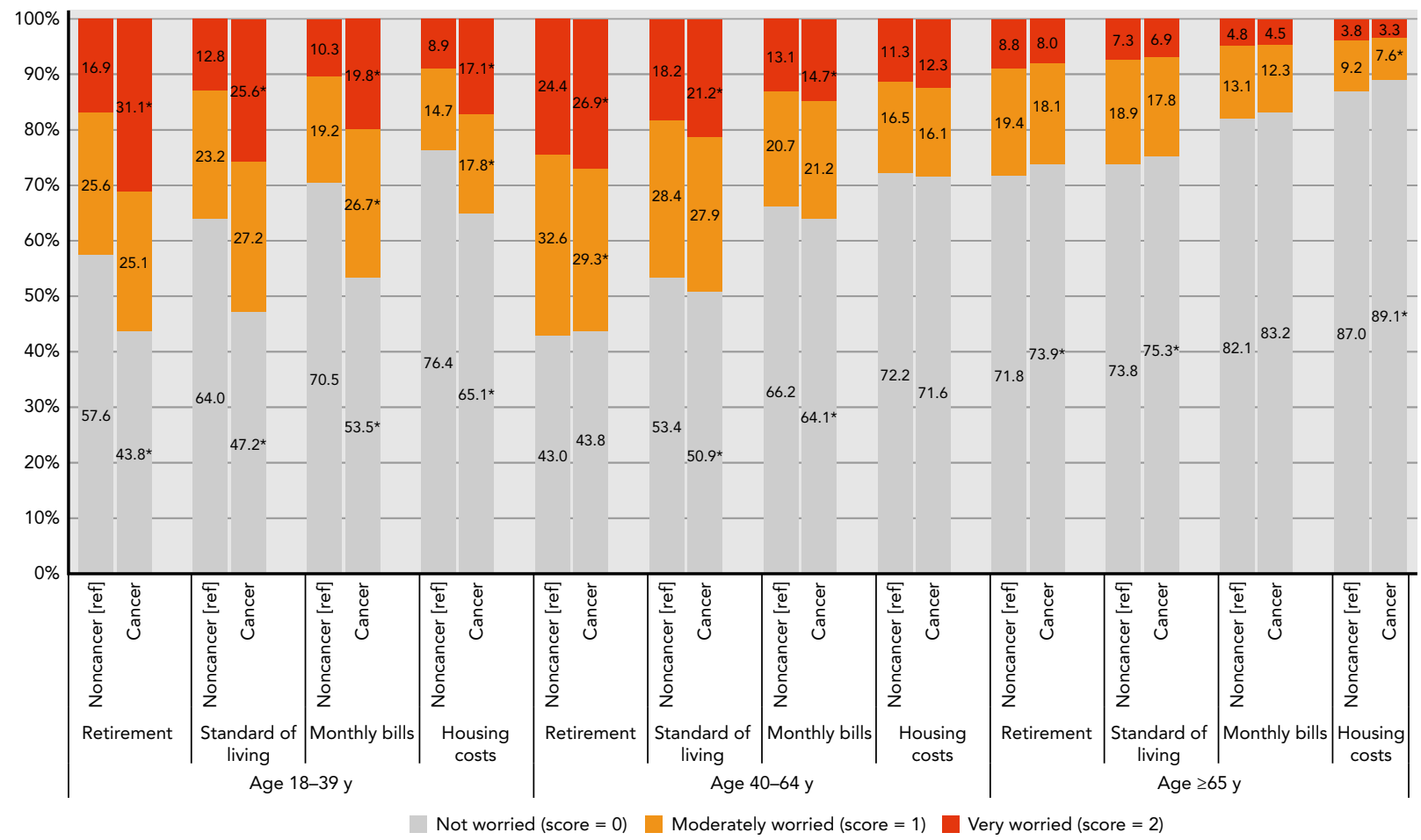

eFigure 3. Unadjusted results of study population reporting individual financial worry measures.

${ }^{*} P<.05$.

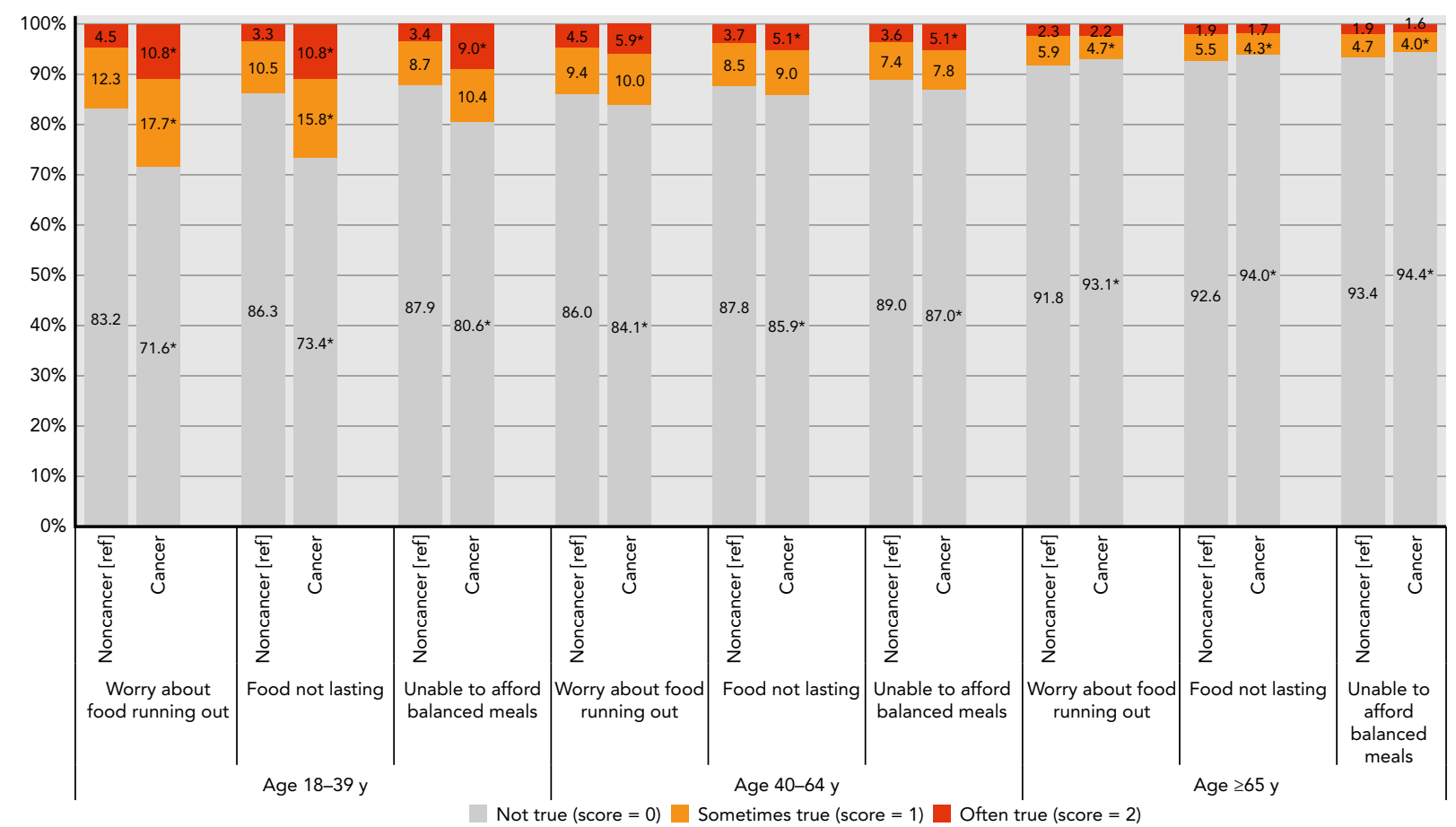

eFigure 4. Unadjusted results of study population reporting individual food insecurity measures.

${ }^{*} P<.05$. 


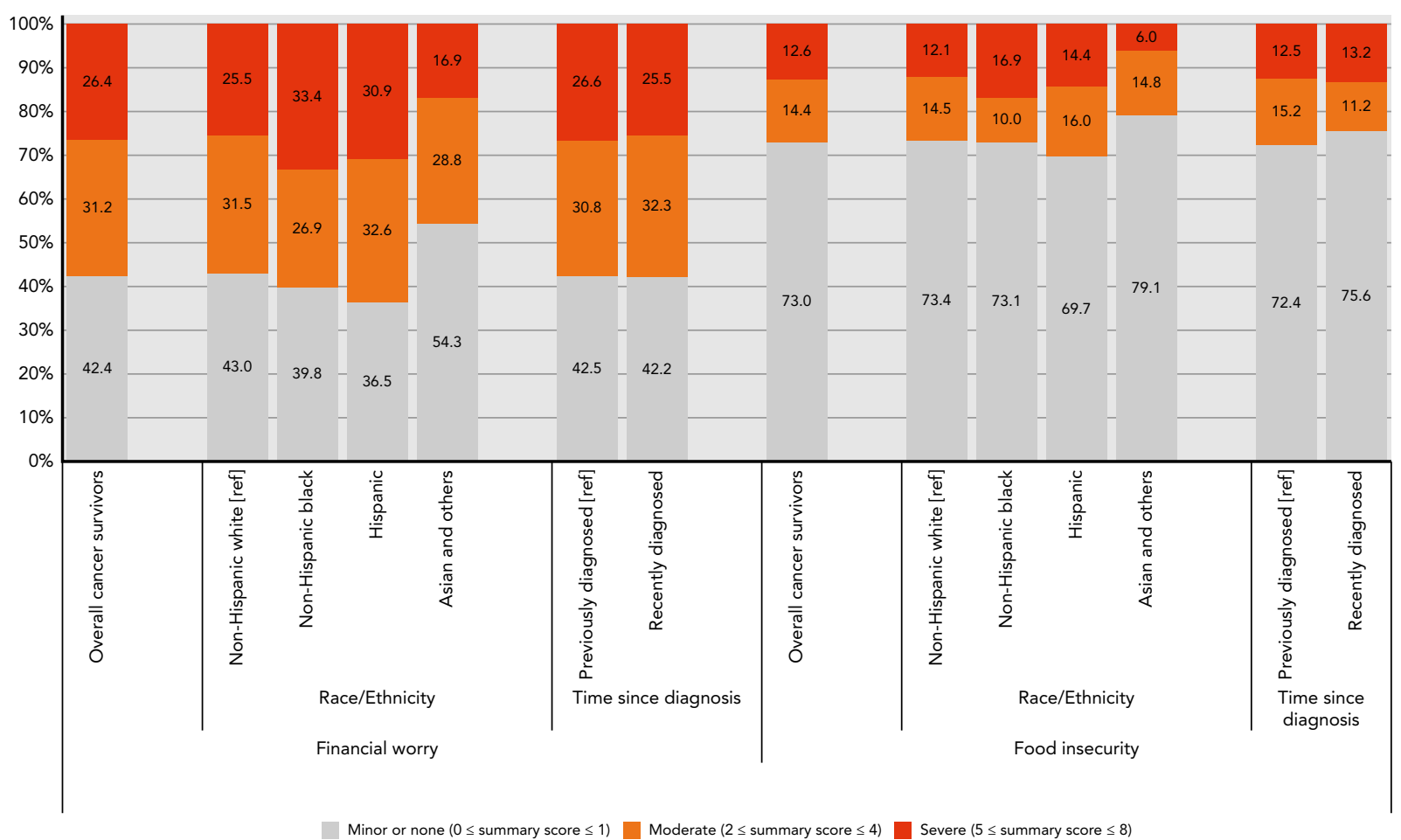

eFigure 5. Adjusted results of financial worry intensity and food insecurity intensity among cancer survivors aged 18-39 years ( $\mathrm{n}=771$ ), stratified by race/ethnicity (non-Hispanic white, $n=545$; non-Hispanic black, $n=59$; Hispanic, $n=114$; Asian and others, $n=53$ ) and time since diagnosis (previously diagnosed, $\geq 2$ years before survey: $n=610$; recently diagnosed, $<2$ years before survey: $n=161$ ). Results for stratification by major cancer sites are not presented because of small sample sizes (female breast, $n=42$; colorectal, $n=16 ;$ prostate, $n=2$; lung, $n=9$; others, $n=702$ ). ${ }^{\star} P<.05$. 


\section{4 - Zheng et al}

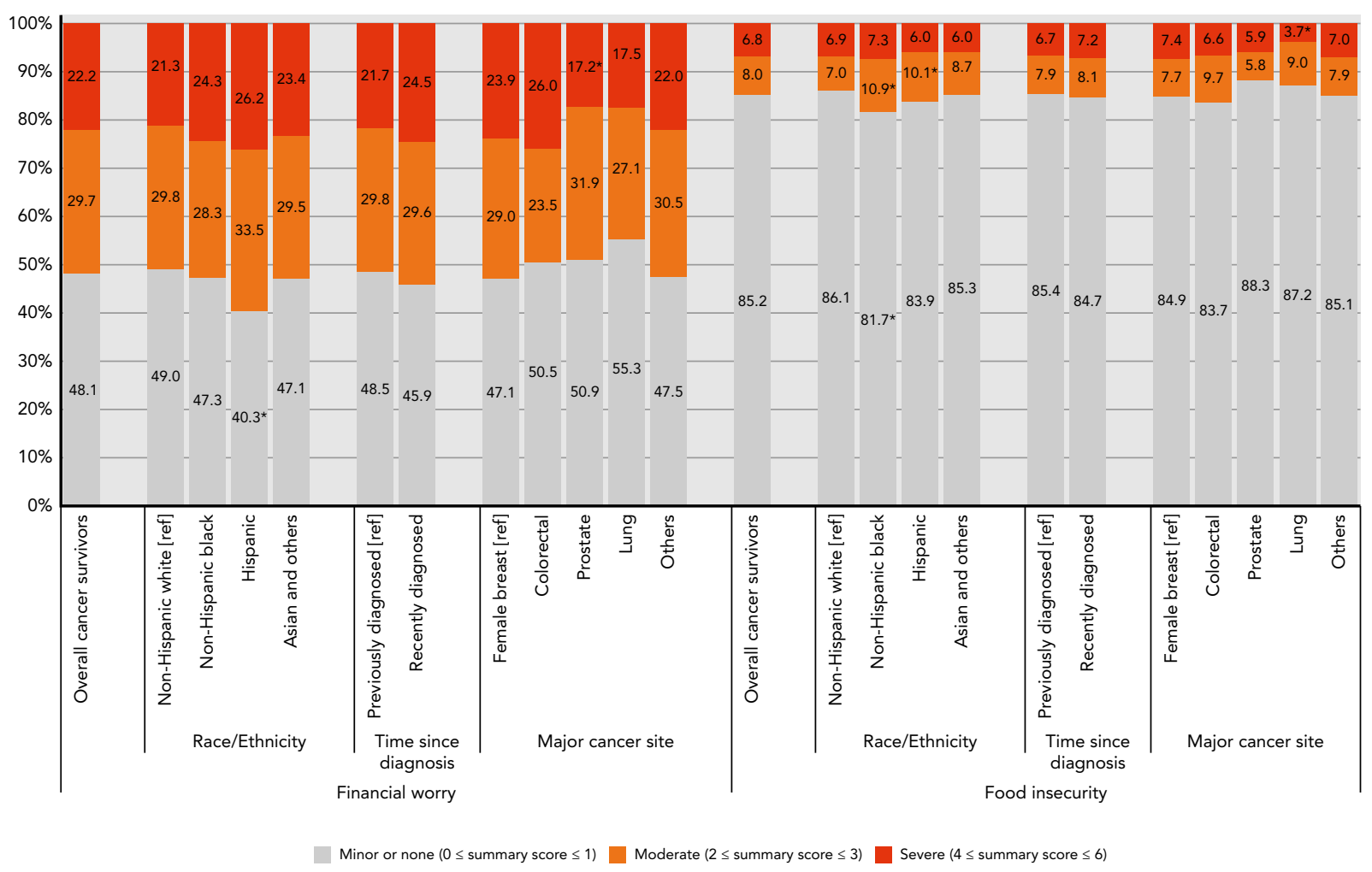

eFigure 6. Adjusted results of financial worry intensity and food insecurity intensity among cancer survivors aged 40-64 years ( $n=4,269)$, stratified by race/ethnicity (non-Hispanic white, $n=3,298$; non-Hispanic black, $n=411$; Hispanic, $n=349$; Asian and others, $n=211$ ), time since diagnosis (previously diagnosed, $\geq 2$ years before survey: $n=3,586$; recently diagnosed, $<2$ years before survey: $n=683$ ), and major cancer site (female breast, $n=943$; colorectal, $n=266$; prostate, $n=326$; lung, $n=128$; others, $n=2,606$ ).

${ }^{\star} P<.05$. 


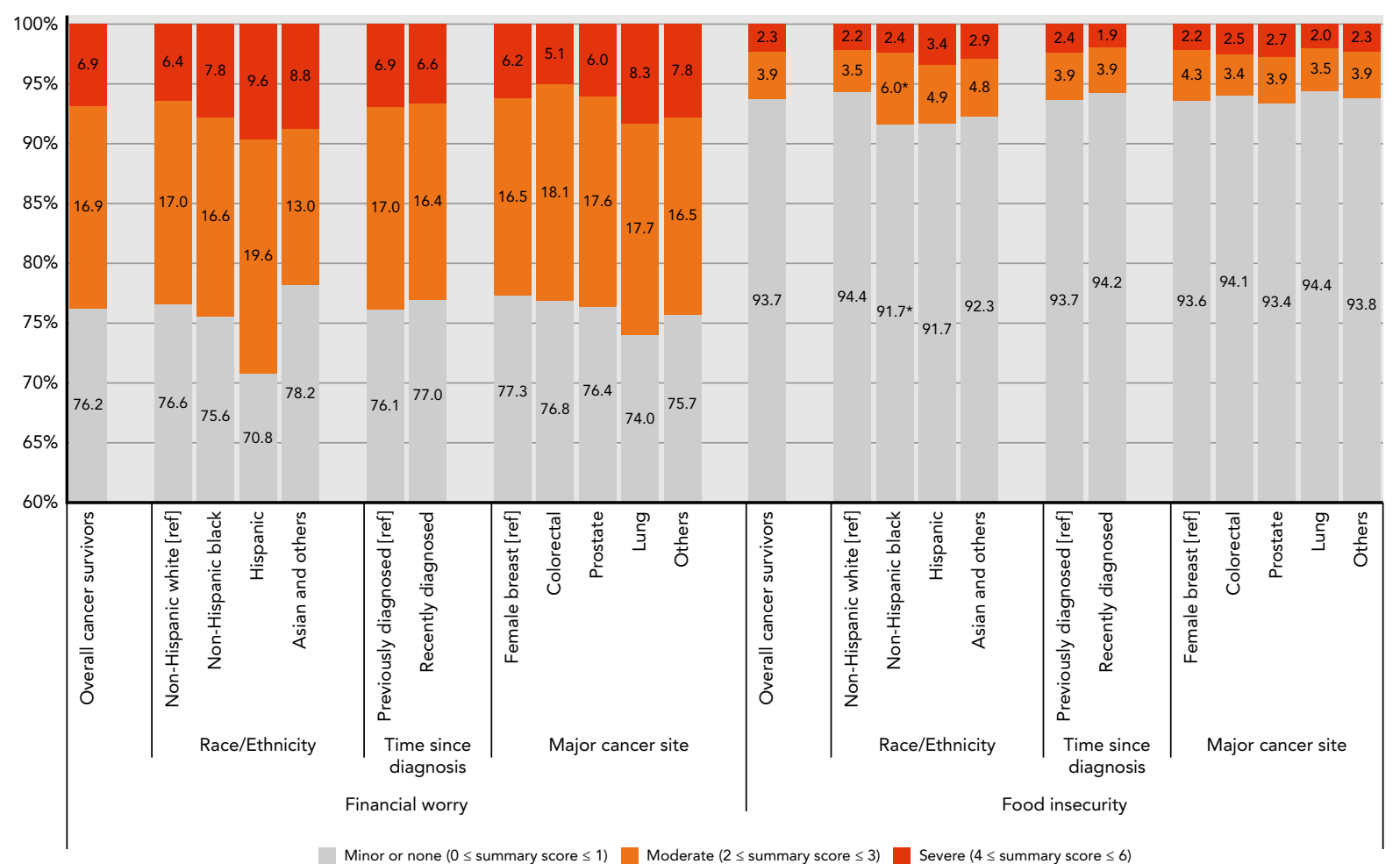

eFigure 7. Adjusted results of financial worry intensity and food insecurity intensity among cancer survivors aged $\geq 65$ years ( $n=7,101$ ), stratified by race/ethnicity (non-Hispanic white, $n=5,795$; non-Hispanic black, $n=633$; Hispanic, $n=370$; Asian and others, $n=303$ ), time since diagnosis (previously diagnosed, $\geq 2$ years before survey: $n=6,068$; recently diagnosed, $<2$ years before survey: $n=1,033$ ), and major cancer site (female breast, $n=1,754$; colorectal, $n=608$; prostate, $n=1,459$; lung, $n=337$; others, $n=2,943$ ).

${ }^{\star} P<.05$. 
eTable 1. NHIS Measures of Food Insecurity and Financial Worry

\begin{tabular}{|c|c|c|c|c|c|}
\hline \multicolumn{2}{|l|}{ Measures } & \multirow{2}{*}{$\begin{array}{l}\text { Universe } \\
\text { Sample adults aged } \\
\geq 18 \text { years }\end{array}$} & \multirow{2}{*}{$\begin{array}{l}\text { NHIS Question } \\
\text { How worried are you right now about not } \\
\text { having enough money for retirement? Are you } \\
\text { very worried, moderately worried, not too } \\
\text { worried, or not worried at all? }\end{array}$} & \multirow{2}{*}{$\frac{\text { Time Frame }}{\text { Current }}$} & \multirow{2}{*}{$\begin{array}{l}\begin{array}{l}\text { Years of } \\
\text { Availability }\end{array} \\
2013-2017\end{array}$} \\
\hline Financial worry & Retirement & & & & \\
\hline & Standard of living & & $\begin{array}{l}\text { How worried are you right now about not } \\
\text { being able to maintain the standard of living } \\
\text { you enjoy? Are you very worried, moderately } \\
\text { worried, not too worried, or not worried at all? }\end{array}$ & & \\
\hline & Monthly bills & & $\begin{array}{l}\text { How worried are you right now about not } \\
\text { having enough to pay your normal monthly } \\
\text { bills? Are you very worried, moderately } \\
\text { worried, not too worried, or not worried at all? }\end{array}$ & & \\
\hline & Housing costs & & $\begin{array}{l}\text { How worried are you right now about not } \\
\text { being able to pay your rent, mortgage, or other } \\
\text { housing costs? Are you very worried, } \\
\text { moderately worried, not too worried, or not } \\
\text { worried at all? }\end{array}$ & & \\
\hline \multirow[t]{3}{*}{ Food insecurity } & Worry about food running out & All; all families & $\begin{array}{l}\text { "[I/We] worried whether [my/our] food would } \\
\text { run out before [l/we] got money to buy more." } \\
\text { Was that often true, sometimes true, or never } \\
\text { true for [you/your family] in the last } 30 \text { days? }\end{array}$ & \multirow[t]{3}{*}{ Past 30 days } & \multirow[t]{3}{*}{ 2011-2017 } \\
\hline & Food not lasting & & $\begin{array}{l}\text { "The food that [l/we] bought just did not last, } \\
\text { and [I/we] did not have money to get more." } \\
\text { Was that often true, sometimes true, or never } \\
\text { true for [you/your family] in the last } 30 \text { days? }\end{array}$ & & \\
\hline & Unable to afford balanced meals & & $\begin{array}{l}\text { "[I/We] could not afford to eat balanced } \\
\text { meals." Was that often true, sometimes true, or } \\
\text { never true for [you/your family] in the last } 30 \\
\text { days? }\end{array}$ & & \\
\hline
\end{tabular}

Abbreviation: NHIS, National Health Interview Survey. 


\section{eTable 2. Unadjusted Results for Financial Worry and Food Insecurity}

\begin{tabular}{lr}
\multicolumn{2}{c}{ Cancer Survivors } \\
\hline$\%$ & $95 \% \mathrm{Cl}$
\end{tabular}

\section{No Cancer History ${ }^{a}$ \\ $\% \quad 95 \% \mathrm{Cl}$}

53,262
Age 18-39 Years, $n$

Financial worry measures

Worry about retirement

Very worried (score $=2$ )

Moderately worried (score $=1$ )

Not worried (score $=0$ )

Worry about standard of living

Very worried (score $=2$ )

Moderately worried (score $=1$ )

Not worried (score $=0$ )

Worry about monthly bills

Very worried (score $=2$ )

Moderately worried (score $=1$ )

Not worried (score $=0$ )

Worry about rent, mortgage, or other housing costs

Very worried (score $=2$ )

Moderately worried (score $=1$ )

Not worried (score $=0$ )

Food insecurity measures

Worry about food running out

Often true (score $=2$ )

Sometimes true (score $=1$ )

Not true (score $=0$ )

Food not lasting

Often true (score $=2$ )

Sometimes true (score $=1$ )

Not true (score $=0$ )

Unable to afford balanced meals

Often true (score $=2$ )

Sometimes true (score $=1$ )

Not true (score $=0$ )

Age 40-64 Years, $n$

Financial worry measures

Worry about retirement

Very worried (score $=2$ )

Moderately worried (score $=1$ )

Not worried (score $=0$ )

Worry about standard of living

Very worried (score $=2$ )

Moderately worried (score $=1$ )

Not worried (score $=0$ )
771

$\begin{array}{ll}31.1 & (26.8-35.4) \\ 25.1 & (20.9-29.3) \\ 43.8 & (39.0-48.6)\end{array}$

16.9

(16.4-17.3) $<.001$

25.6

(25.1-26.1)

.834

57.6

(56.9-58.2)

$<.001$

$\begin{array}{rrrrr}25.6 & (21.5-29.8) & 12.8 & (12.4-13.3) & <.001 \\ 27.2 & (22.8-31.5) & 23.2 & (22.7-23.7) & .076 \\ 47.2 & (42.4-52.0) & 64.0 & (63.3-64.6) & <.001\end{array}$

$\begin{array}{rrrrr}19.8 & (16.0-23.6) & 10.3 & (9.9-10.7) & <.001 \\ 26.7 & (22.2-31.2) & 19.2 & (18.7-19.8) & .001 \\ 53.5 & (48.6-58.4) & 70.5 & (69.8-71.1) & <.001\end{array}$

53.5

(48.6-58.4)

70.5

(13.6-20.6)

8.9

(8.5-9.3)

$<.001$

(13.8-21.8)

14.7

(14.2-15.1)

.124

(60.3-69.8)

76.4

(75.9-77.0)

$<.001$

(7.7-13.9)

(13.5-21.8)

(66.8-76.3)

(7.0-14.5)

(12.4-19.3)

(68.7-78.0)

(6.1-11.8)

(7.8-13.0)

(77.0-84.3)

4,269

\section{9}

29.3

43.8

21.2

27.9

50.9
(25.1-28.7)

(27.3-31.3)

(41.8-45.8)

(19.6-22.8)

(26.1-29.6)

(49.0-52.8)
4.5

12.3

83.2

3.3

10.5

86.3

3.4

8.7

8.7

87.9

60,14

(4.3-4.8)

$<.001$

(11.9-12.7)

.012

(82.6-83.7)

$<.001$

$<.001$

(3.1-3.5)

$<.001$

(10.1-10.9)

.003

(85.8-86.7)

$<.001$

(3.2-3.6)

$<.001$

(8.3-9.0)

.190

(87.5-88.3)

.190
$<.001$

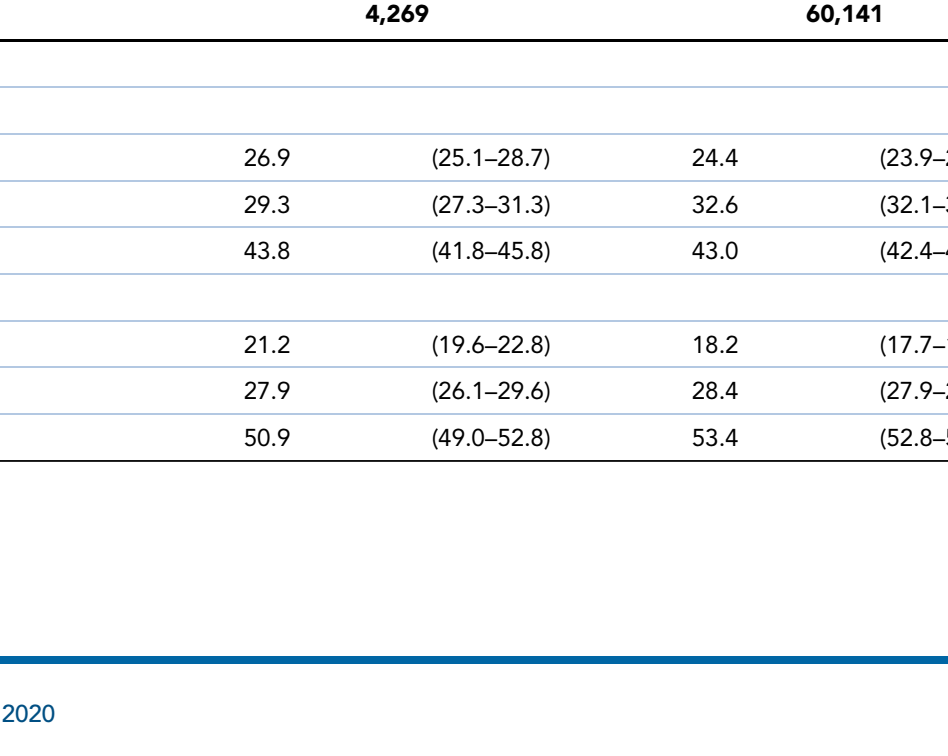


eTable 2. Unadjusted Results for Financial Worry and Food Insecurity (cont.)

\begin{tabular}{|c|c|c|c|c|c|}
\hline & \multicolumn{2}{|c|}{ Cancer Survivors } & \multicolumn{2}{|c|}{ No Cancer History ${ }^{a}$} & \multirow[b]{2}{*}{$P$ Value } \\
\hline & $\%$ & $95 \% \mathrm{Cl}$ & $\%$ & $95 \% \mathrm{Cl}$ & \\
\hline \multicolumn{6}{|l|}{ Worry about monthly bills } \\
\hline Moderately worried (score $=1$ ) & 21.2 & $(19.6-22.8)$ & 20.7 & $(20.3-21.2)$ & .569 \\
\hline Not worried (score $=0$ ) & 64.1 & $(62.2-66.0)$ & 66.2 & $(65.6-66.8)$ & .030 \\
\hline Very worried (score $=2$ ) & 12.3 & $(11.0-13.6)$ & 11.3 & $(10.9-11.7)$ & .127 \\
\hline Moderately worried (score $=1$ ) & 16.1 & $(14.6-17.5)$ & 16.5 & $(16.0-16.9)$ & .615 \\
\hline Not worried (score $=0$ ) & 71.6 & $(69.8-73.4)$ & 72.2 & $(71.7-72.8)$ & .507 \\
\hline \multicolumn{6}{|l|}{ Food insecurity measures } \\
\hline \multicolumn{6}{|l|}{ Worry about food running out } \\
\hline \multicolumn{6}{|l|}{ Food not lasting } \\
\hline Often true (score $=2$ ) & 5.1 & $(4.3-5.8)$ & 3.7 & $(3.5-3.9)$ & .001 \\
\hline Sometimes true $($ score $=1)$ & 9.0 & $(8.0-10.1)$ & 8.5 & $(8.2-8.8)$ & .351 \\
\hline Not true $($ score $=0$ ) & 85.9 & $(84.6-87.2)$ & 87.8 & (87.4-88.2) & .004 \\
\hline \multicolumn{6}{|l|}{ Unable to afford balanced meals } \\
\hline Often true (score $=2$ ) & 5.1 & $(4.4-5.9)$ & 3.6 & $(3.4-3.8)$ & $<.001$ \\
\hline Sometimes true $($ score $=1)$ & 7.8 & $(6.9-8.8)$ & 7.4 & $(7.1-7.7)$ & .412 \\
\hline Not true $($ score $=0)$ & 87.0 & $(85.8-88.3)$ & 89.0 & $(88.6-89.4)$ & .002 \\
\hline Age $\geq 65$ Years, $n$ & \multicolumn{2}{|c|}{7,101} & \multicolumn{2}{|c|}{30,261} & \\
\hline Very worried (score $=2$ ) & 6.9 & $(6.2-7.6)$ & 7.3 & $(6.9-7.7)$ & .330 \\
\hline Moderately worried (score $=1$ ) & 17.8 & $(16.6-19.0)$ & 18.9 & $(18.3-19.5)$ & .097 \\
\hline Not worried (score $=0$ ) & 75.3 & $(74.0-76.7)$ & 73.8 & $(73.0-74.5)$ & .048 \\
\hline \multicolumn{6}{|l|}{ Worry about monthly bills } \\
\hline Very worried (score $=2$ ) & 4.5 & $(3.9-5.2)$ & 4.8 & $(4.5-5.2)$ & .419 \\
\hline Moderately worried (score $=1$ ) & 12.3 & $(11.3-13.4)$ & 13.1 & $(12.5-13.7)$ & .197 \\
\hline Not worried (score $=0$ ) & 83.2 & $(82.0-84.3)$ & 82.1 & $(81.4-82.7)$ & .115 \\
\hline \multicolumn{6}{|c|}{ Worry about rent, mortgage, or other housing costs } \\
\hline Very worried (score $=2$ ) & 3.3 & $(2.8-3.8)$ & 3.8 & $(3.5-4.1)$ & .086 \\
\hline Moderately worried (score $=1$ ) & 7.6 & $(6.8-8.5)$ & 9.2 & $(8.7-9.7)$ & .001 \\
\hline Not worried (score $=0$ ) & 89.1 & $(88.1-90.0)$ & 87.0 & (86.4-87.5) & $<.001$ \\
\hline
\end{tabular}




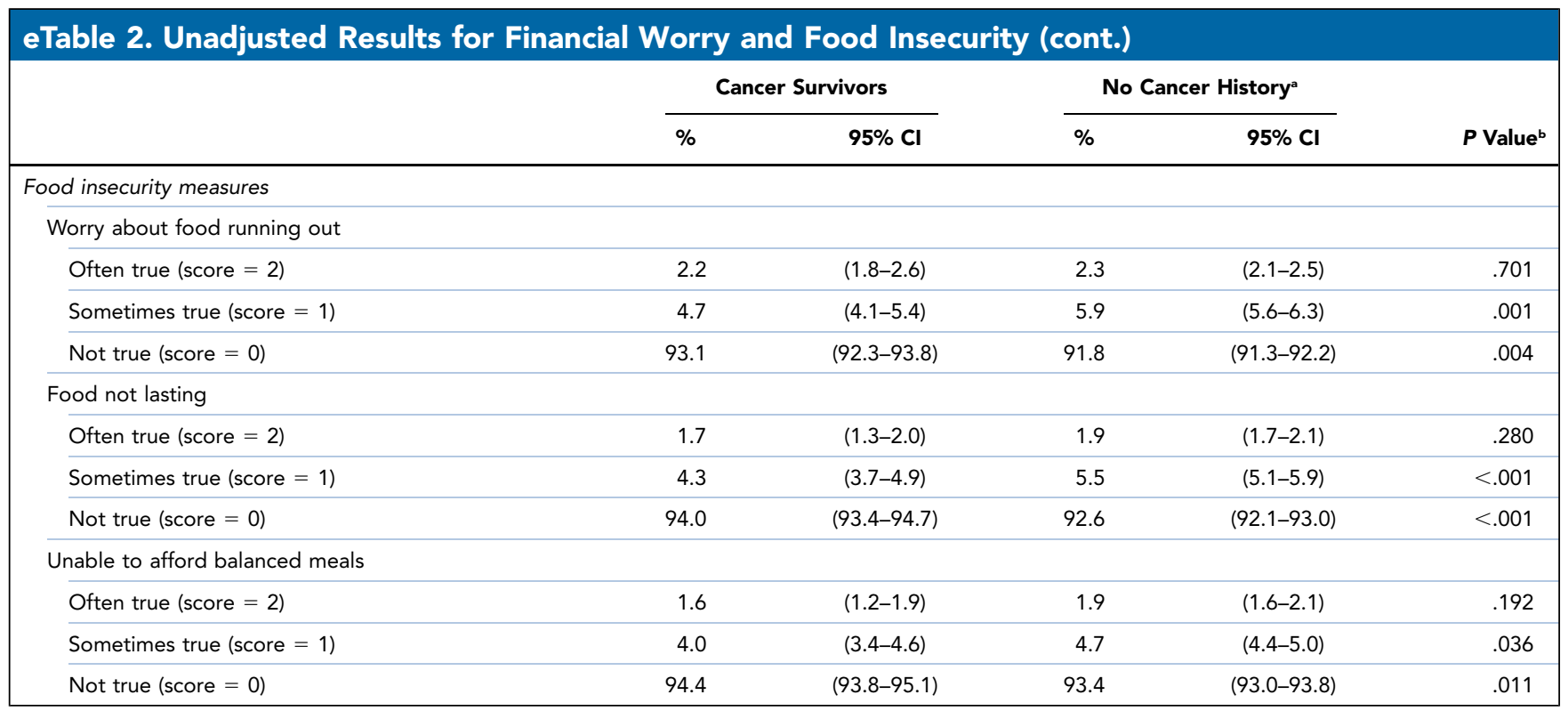

Detailed survey questions are shown in supplemental eTable 1.

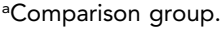

${ }^{b}$ All statistical tests were 2-sided, and all $P$ values were derived from generalized multivariable adjusted ordinal logistic regressions. 